\title{
Cocaine Self-Administration Experience Induces Pathological Phasic Accumbens Dopamine Signals and Abnormal Incentive Behaviors in Drug-Abstinent Rats
}

\author{
๑Dichael P. Saddoris, ${ }^{1,2}$ - Xuefei Wang, ${ }^{2}$ - Jonathan A. Sugam, ${ }^{2}$ and Regina M. Carelli2 ${ }^{2}$ \\ 'Department of Psychology and Neuroscience, University of Colorado, Boulder, Colorado 80309, and ${ }^{2}$ Department of Psychology and Neuroscience, \\ University of North Carolina at Chapel Hill, Chapel Hill, North Carolina 27599
}

\begin{abstract}
Chronic exposure to drugs of abuse is linked to long-lasting alterations in the function of limbic system structures, including the nucleus accumbens (NAc). Although cocaine acts via dopaminergic mechanisms within the NAc, less is known about whether phasic dopamine (DA) signaling in the NAc is altered in animals with cocaine self-administration experience or if these animals learn and interact normally with stimuli in their environment. Here, separate groups of rats self-administered either intravenous cocaine or water to a receptacle (controls), followed by $30 \mathrm{~d}$ of enforced abstinence. Next, all rats learned an appetitive Pavlovian discrimination and voltammetric recordings of real-time DA release were taken in either the NAc core or shell of cocaine and control subjects. Cocaine experience differentially impaired DA signaling in the core and shell relative to controls. Although phasic DA signals in the shell were essentially abolished for all stimuli, in the core, DA did not distinguish between cues and was abnormally biased toward reward delivery. Further, cocaine rats were unable to learn higher-order associations and even altered simple conditioned approach behaviors, displaying enhanced preoccupation with cue-associated stimuli (sign-tracking; ST) but diminished time at the food cup awaiting reward delivery (goal-tracking). Critically, whereas control DA signaling correlated with ST behaviors, cocaine experience abolished this relationship. These findings show that cocaine has persistent, differential, and pathological effects on both DA signaling and DA-dependent behaviors and suggest that psychostimulant experience may remodel the very circuits that bias organisms toward repeated relapse.
\end{abstract}

Key words: Incentive salience; prediction error; sign tracking; ventral striatum; voltammetry

Significance Statement

Relapsing to drug abuse despite periods of abstinence and sincere attempts to quit is one of the most pernicious facets of addiction. Unfortunately, little is known about how the dopamine (DA) system functions after periods of drug abstinence, particularly its role in behavior in nondrug situations. Here, rats learned about food-paired stimuli after prolonged abstinence from cocaine selfadministration. Using voltammetry, we found that real-time DA signals in cocaine-experienced rats were strikingly altered relative to controls. Further, cocaine-experienced animals found reward-predictive stimuli abnormally salient and spent more time interacting with cues. Therefore, cocaine induces neuroplastic changes in the DA system that biases animals toward salient stimuli (including reward-associated cues), putting addicts at increasing risk to relapse as addiction increases in severity.

\section{Introduction}

The transition from drug use to addiction has profound negative consequences. Therefore, addicted persons typically make sincere

\footnotetext{
Received Sept. 16, 2015; revised Nov. 5, 2015; accepted Nov. 24, 2015.

Author contributions: M.P.S. designed research; M.P.S., X.W., and J.A.S. performed research; M.P.S. analyzed data; M.P.S., X.W., J.A.S., and R.M.C. wrote the paper.

This work was supported by the National Institute on drug Abuse (Grant DA035322 to M.P.S. and Grant DA034021 to R.M.C.). We thank Douglas Terry, Jason Reid, and Aimee Rogers for outstanding work in assisting with video scoring and Robert Edmiston for assistance with behavior.

The authors declare no competing financial interests.

Correspondence should be addressed to Dr. Michael P. Saddoris, Department of Psychology and Neuroscience, University of Colorado Boulder, UCB 345, Boulder, C0 80309-0345. E-mail: michael.saddoris@colorado.edu.
}

efforts to abstain from drug use only to undergo persistent cycles of relapse triggered by reexperiencing drug-associated stimuli. These stimuli can elicit powerful feelings of craving and negative affective states, inducing the addicted person to seek out drugs to alleviate the negative emotional state and motivational withdrawal (Ehrman et al., 1992; Ahmed and Koob, 1998; Robbins et al., 2000; Pickens et al., 2011; Koob, 2015). In addition, addicted persons are also more likely to exhibit changes in behavior in nondrug situations such as increased risk taking, impulsivity, and decreases in motivation toward 
effortful activities (Goldstein et al., 2007; Vadhan et al., 2009; Moeller et al., 2012a,b; Canavan et al., 2014) even after periods of abstinence from the drug. These findings suggest that chronic drug use induces long-term plastic changes in neural circuits that normally process stimuli and prospective valuation (Wheeler et al., 2011; Wolf and Tseng, 2012; Twining et al., 2015).

Dopamine (DA) afferents from the ventral tegmental area (VTA) are implicated in supporting these functions. Although drugs of abuse either directly or indirectly act to increase DA release within the nucleus accumbens (NAc) (Di Chiara and Imperato, 1988), phasic DA release in the NAc of drug-naive animals has been shown to encode aspects of learning and motivated behavior, such as prediction errors (Schultz et al., 1997; Saddoris et al., 2015a), incentive salience (Flagel et al., 2011; Saddoris et al., 2015a), and the value of anticipated outcomes (Sugam et al., 2012; Saddoris et al., 2015b). Neuroimaging evidence has shown that chronic cocaine use is associated with multiple changes in both DA circuit and receptor function (Volkow et al., 1993; Volkow et al., 1996; Asensio et al., 2010; Konova et al., 2012). However, in human populations, it can be difficult to assess whether cocaine experience induces behavioral changes or if predispositions toward risk taking and impulsivity (e.g., via genetic or epigenetic factors) creates a greater propensity for developing addiction than the rest of the population (Boettiger et al., 2007; Kelm and Boettiger, 2013).

Animal studies have shown that repeated cocaine experience induces persistent changes in mesolimbic circuit processing. Cocaineexperienced animals show marked difficulties in flexibly altering behavior by perseverating on actions that are no longer rewarded (Jentsch et al., 2002; Schoenbaum et al., 2004; Calu et al., 2007; Stalnaker et al., 2007a) and inappropriately approaching stimuli predictive of foods that have become aversive (Schoenbaum and Setlow, 2005; LeBlanc et al., 2013). Furthermore, cocaine experience appears to abolish the ability of cues to support appropriate value-based behaviors, driving subjects toward more impulsive choices (Simon et al., 2007; Setlow et al., 2009) and impairing the use of learned stimuli to support new learning and behavior (Saddoris et al., 2011; LeBlanc et al., 2013; Saddoris and Carelli, 2014).

Although these behavioral deficits are related to DA-dependent tasks, less is known about whether cocaine experience itself causes persistent changes in DA signaling within the NAc. One recent study using fast-scan cyclic voltammetry (FSCV) demonstrated that the amount of striatal DA release to cocaine-related cues during selfadministration sessions strongly decreased over repeated sessions (Willuhn et al., 2014). However, because this task was done while the drug was on-board and with drug-related stimuli, it is difficult to disentangle the acute effects of the drug from any longlasting neuroplastic changes to the mesolimbic DA system, which may be maintained well after drug abstinence. Further, because DA signals differentially encode information between core and shell in normal animals (Cacciapaglia et al., 2012; Saddoris et al., 2013; Chuhma et al., 2014; Saddoris et al., 2015a), it is unclear whether cocaine experience would differentially affect DA signaling patterns in these NAc subregions. Here, using FSCV, we recorded real-time DA release in the NAc core and shell in both controls and cocaine-experienced subjects (after $30 \mathrm{~d}$ of selfadministration abstinence) after they learned Pavlovian discriminations.

\section{Materials and Methods Animals}

Male Sprague Dawley rats $(n=35)$ initially weighing $\sim 300 \mathrm{~g}$ were used as subjects. Animals were individually housed with a $12 \mathrm{~h} / 12 \mathrm{~h}$ light/dark cycle. During water-restricted portions of the experiment, all rats re- ceived $20 \mathrm{ml} / \mathrm{d}$ water in the home cage plus additional fluids collected during the task. On food-restricted training and test days, rats were maintained at no less than $90 \%$ of free feed body weight via food restriction that included $10-15 \mathrm{~g}$ of Purina laboratory chow in the home cage each day in addition to $\sim 2.7 \mathrm{~g}$ of sucrose consumed during daily sessions. Food or water restriction was in place for the duration of behavioral testing days except during the postsurgery recovery period, when food and fluids were given ad libitum. All procedures were performed in accordance with the University of North Carolina at Chapel Hill Institutional Animal Care and Use Committee.

\section{Behavioral methods}

Rats were trained in a series of tasks starting with self-administration, followed by a period of enforced abstinence ( $30 \mathrm{~d}$ ), and then training on a Pavlovian first-order conditioning (FOC) task. Finally, to assess the animals' motivation for drug taking, a final extinction session in the self-administration chamber was administered. A schematic of the task phases and timing of surgical procedures appears in Figure $1 A$ and detailed descriptions of all experimental procedures are described below.

\section{Cocaine self-administration}

Rats were first aseptically surgically prepared for an indwelling intrajugular catheter as described in detail previously (Saddoris et al., 2011). After 1 week of recovery, rats were lightly water deprived and then trained on a standard self-administration regimen as described previously (Saddoris et al., 2011; Saddoris and Carelli, 2014). Briefly, in a standard selfadministration chamber (context A: $25 \times 25 \times 30 \mathrm{~cm}$, stainless steel rod floor; MED Associates), cocaine rats $(n=15)$ were connected via flexible tubing to a syringe containing cocaine $(1.67 \mathrm{mg} / \mathrm{ml}$ in $0.9 \%$ saline $)$ to the intrajugular catheter. A swivel connecting tubing and the syringe allowed free movement in the test chamber. At the onset of each $2 \mathrm{~h}$ session, a lever was extended into the chamber and a cue light was illuminated over the lever. Presses on the lever delivered an intravenous infusion for $6 \mathrm{~s}$ ( $0.33 \mathrm{mg}$ of cocaine in $200 \mu \mathrm{l}$ of saline) commensurate with lever retraction, cue light extinguishing, house light illumination, and an intermittent $1 \mathrm{~Hz}$ "beeping" tone $(1200 \mathrm{~Hz})$ for $20 \mathrm{~s}$. After $20 \mathrm{~s}$, all conditioned reinforcing stimuli were extinguished and the lever and cue light were once again presented in the chamber. For control rats $(n=20)$, presses on the illuminated lever delivered a bolus of water $(250 \mu \mathrm{l})$ to a recessed food cup to maintain similar instrumental performance as cocaine subjects. As with cocaine self-administration, presses were accompanied by the conditioned reinforcing stimuli (tone/houselight) and lever retraction for $20 \mathrm{~s}$. Controls were also connected to an intravenous catheter connected to a pump, but received yoked $0.9 \%$ saline infusions based on the schedule of an adjacent cocaine-administering rat. Sessions were $2 \mathrm{~h}$ and rats performed this task daily for $14 \mathrm{~d}$. At the completion of selfadministration, rats were placed on unrestricted food and water access and remained in their home cages until a second surgery to implant FSCV cannulae (3 weeks). Rats were allowed an additional week of recovery after cannula implants, so the Pavlovian discrimination testing began 4 weeks after the end of the self-administration sessions.

\section{FSCV}

After self-administration sessions and 1 week before the start of Pavlovian training, rats were prepared for electrochemical recording using FSCV as described in detail previously (Cacciapaglia et al., 2012). Briefly, rats were implanted with a guide cannula over the NAc core $(\mathrm{AP}:+1.3$ $\mathrm{mm}, \mathrm{ML}:+1.3 \mathrm{~mm}$ relative to bregma) or shell (AP: $+1.3 \mathrm{~mm}, \mathrm{ML}:+0.8$ $\mathrm{mm}$ relative to bregma) while a second cannula in the contralateral hemisphere was used to hold an acutely implanted $\mathrm{Ag} / \mathrm{AgCl}$ reference. A bipolar stimulating probe was positioned near the VTA to allow for electrical stimulation of ascending fibers to the NAc. Rats were given 1 week to recover before beginning behavioral testing. On the test day, the acute $\mathrm{Ag} / \mathrm{AgCl}$ reference was inserted and an acute carbon fiber electrode was lowered into the core via a drivable manipulator. An applied voltage $(-0.4$ to $+1.3 \mathrm{~V})$ resulted in changes in current at the carbon fiber tip. Changes in current at the oxidation potentiation for DA were compared with electrically stimulated DA release at the same location and chemo- 


\section{A}

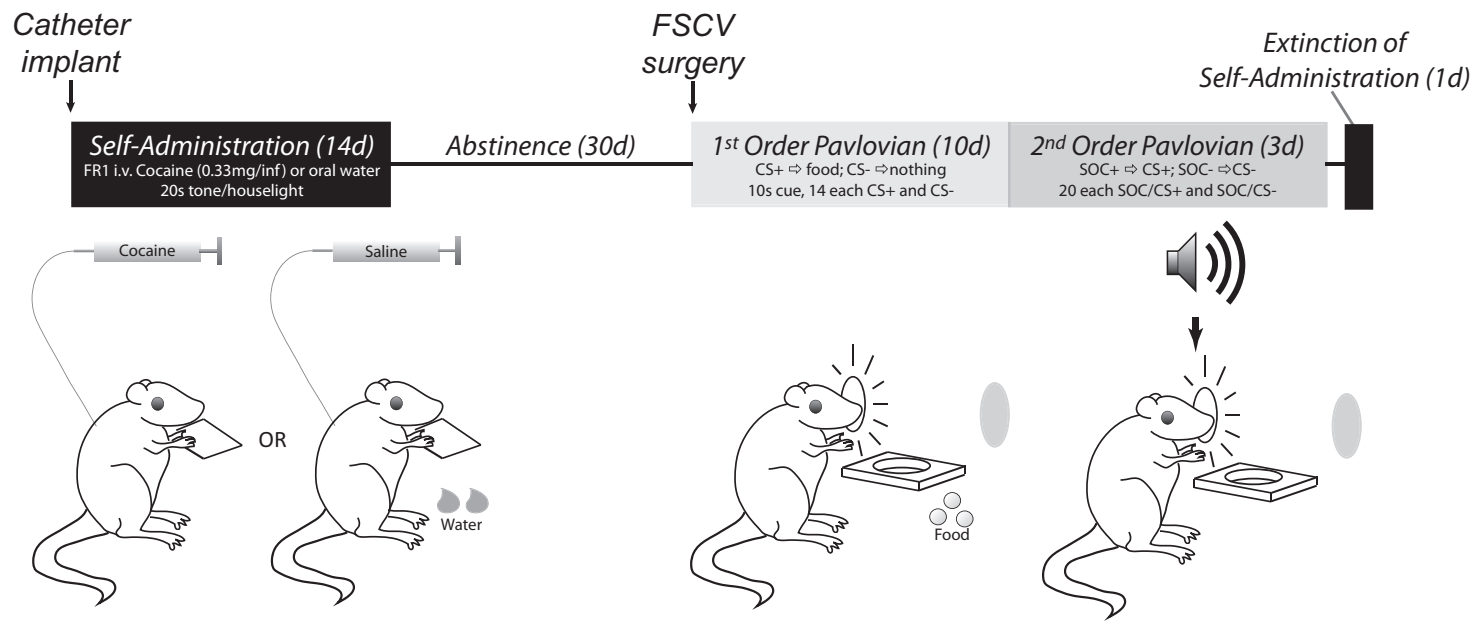

B

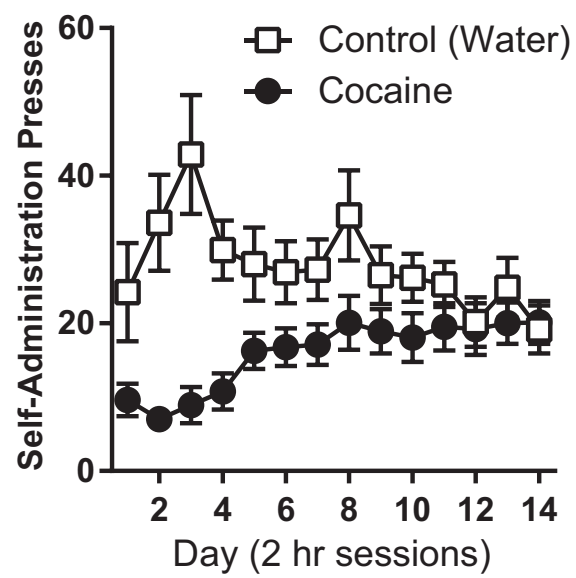

C

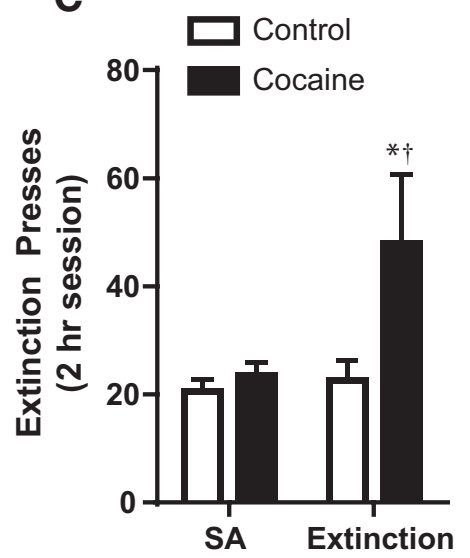

Figure 1. A, Schematic of task phases. Self-administration sessions were $2 \mathrm{~h}$ per day for $14 \mathrm{~d}$. Final extinction session was also $2 \mathrm{~h}$. $\boldsymbol{B}$, Rewarded self-administration presses for controls (open squares; water delivered to receptacle, yoked intravenous saline infusion; $n=20$ ) and cocaine-administering subjects (black circles; $0.33 \mathrm{mg} /$ inf i.v. cocaine; $n=15$ ). $\boldsymbol{C}$, Presses on the self-administration lever under extinction conditions after extended abstinence (control: $n=13$; cocaine, $n=7$ ). ${ }^{*} p<0.05$, last $5 \mathrm{~d}$ self-administration versus extinction; $\nmid p<0.05$, control vs cocaine.

metric analysis was used to identify DA concentrations using HDCV software (UNC Chemistry Electronics) and aligned to behavioral events (Trans IV; MED Associates).

\section{Pavlovian discriminations}

After self-administration, all rats were trained in a standard Pavlovian FOC task in a test chamber easily discriminable from the drug selfadministration chamber (context B: $43 \times 43 \times 53 \mathrm{~cm}$, smooth Plexiglas floors; MED Associates) as described previously (Saddoris and Carelli, 2014). During all Pavlovian conditioning sessions, rats were lightly food deprived (90-95\% of free feed weight). Briefly, on each trial, rats were presented with one of two discriminable visual stimuli (solid cue light on one side of the chamber wall, flashing cue light on the opposite side) for $10 \mathrm{~s}$. One cue (conditioned stimulus positive; CS + ) was partially reinforced such that it predicted delivery of food ( 3 sucrose pellets, $45 \mathrm{mg}$; Purina TestDiet) on 12 of the 14 trials, whereas the other two CS + trials had food omitted. The other cue (CS-) was never reinforced (14 presentations). Rats learned this discrimination over $10 \mathrm{~d}$. Sessions were 83 min long and the average intertrial interval was $180 \pm 90 \mathrm{~s}$.

A subset of rats ( $n=20$ control, 10 cocaine) performed further second-order conditioning (SOC) in the same chamber. In SOC, in the session after the last day of first-order training, rats received a training day (SOCd0) when they were exposed to $1010 \mathrm{~s}$ nonreinforced presentations of 2 distinct auditory cues (white noise or $600 \mathrm{~Hz}$ tone; 5 presentations each) to extinguish any noncontingent behavioral changes in the presence of the sounds. On 3 subsequent test days (SOCd1-3), rats received 18 pairings of a $10 \mathrm{~s}$ audio cue (e.g., white noise; $\mathrm{SOC}+$ ) immediately followed by the $10 \mathrm{~s}$ CS + and 17 pairings of the other $10 \mathrm{~s}$ audio cue (e.g., tone; SOC-) followed by the $10 \mathrm{~s}$ CS - . Neither pairing was followed by food reinforcement. However, 24 "reminder trials" (12 CS+, $12 \mathrm{CS}-$ ) were delivered during the session: 12 at session onset ( $6 \mathrm{CS}+, 6$ $\mathrm{CS}-$ ), 6 during the session ( $3 \mathrm{CS}+, 3 \mathrm{CS}-$ ), and 6 at the end of the session (3 CS,$+ 3 \mathrm{CS}-$ ). Both reminder cues were reinforced as during first-order sessions.

\section{Drug extinction}

At the conclusion of all Pavlovian conditioning sessions, a subset of rats was returned to free feed and lightly water deprived $(20 \mathrm{ml} / \mathrm{d})$. On a single day of testing, rats were connected to catheter tubing in context A and placed in the original self-administration chamber. However, this catheter tubing was not connected to any solutions (cocaine or vehicle), nor was water connected to the food cup. Rats were run on the same experimental procedures as during self-administration $(2 \mathrm{~h})$ in which presses 
on the lever produced an audiovisual stimulus for $20 \mathrm{~s}$ along with lever retraction, but no drug or water reinforcement was delivered.

\section{Data analysis}

For self-administration, we averaged the number of reinforced presses by the group on each day. To calculate extinction, we compared the average number of presses during the last $5 \mathrm{~d}$ of self-administration to the number of presses in extinction. Likewise, drug loading was considered to be the number of presses during the first $5 \mathrm{~min}$ of a self-administration session. To ensure that this number was stable, we used the average number of loading presses over the last $5 \mathrm{~d}$ of self-administration.

For Pavlovian conditioning, we examined associative behaviors (cue approaches, food cup approaches) during the $10 \mathrm{~s}$ baseline period immediately preceding each cue onset and compared that with the same behaviors during cue presentation (10 s) and after reward delivery (10 s).

To quantify associative behaviors in FOC, we first used automated head entry detectors mounted immediately above the food cup. Interruption of the beam when the rat was directly engaged in the food cup itself generated timestamps to count the number of approaches in the session, as we have done in previous studies (Saddoris and Carelli, 2014). For each subject, the average number of head entries was taken in each $10 \mathrm{~s}$ bin (i.e., baseline, cue, reward) during the different cue types (i.e., $\mathrm{CS}+, \mathrm{CS}-$ ). Mixed-model ANOVA analyses were performed using drug (control vs cocaine) as a between-subjects factor while behavioral measures were examined within subjects as they progressed through each time bin (baseline, cue, reward), between different cues (CS+ trials versus CS - trials) and across days (day 1-10). Note that, for CS + trials, only 12 of the 14 trials were reinforced with food. Therefore, for analyses looking specifically at cues, all CS + trials $(n=14)$ were used regardless of reinforcement (because the subject had no way of knowing whether the trial would be reinforced). However, for reward analysis or any analysis directly comparing reward and cues, only the trials in which reinforcers were delivered $(n=12)$ were used. Likewise, head entry behavior was separately examined by mixed-model ANOVA for SOC days using $10 \mathrm{~s}$ bin (baseline, SOC, and FOC), cue types (SOC+, SOC-), and day (SOCD1-3) to assess conditioning.

Next, behavior was quantified to understand the differences in appetitive approach during associative stimuli. Video-recorded sessions of behavior on days 1,5 , and 10 of FOC were scored by raters who were blind to the subject's drug history. Zones $\left(1.5^{\prime \prime} \times 1.5\right.$ ") were created around the cue lights and food cup and raters manually scored when the rat's head entered and exited the zones using keystrokes in Plexon's SortClient software. Behavior was scored during the $10 \mathrm{~s}$ baseline and $10 \mathrm{~s}$ cue period for all CS + and CS - trials. Because it has been shown that the dominant form of conditioned approach behavior can change between the beginning and end of cue presentations, we separately examined behavior in the first $5 \mathrm{~s}$ of the cue (early phase) and the second $5 \mathrm{~s}$ of the cue (late phase). In a separate analysis, we also examined approach behaviors to the reward by comparing the same pre-cue baseline to the first $5 \mathrm{~s}$ after reward delivery. Sign tracking (approach cue; ST) and goal tracking (approach food cup; GT) behavior was generated by assessing multiple factors including: percentage of time within each zone (CS+, CS-, food cup), probability of approach to each of the stimuli, number of discrete entries into the zones, and latency to approach. For the latency measure ("first contact"), whichever stimulus zone was approached first by the animal in each trial (e.g., CS+ light) was scored as a " 1 " and the other stimuli on that trial (e.g., food cup, CS - light) as "0". The first contact index was generated by subtracting the average first contract score for the food cup from the first contact score from the cue. Therefore, the range of scores were between +1 (all trials in which the rat approached the CS first) and -1 (all trials in which the rat approached the food cup first).

To classify subjects as ST or GT, we computed a Pavlovian conditioned approach (PCA) index, modified from the commonly used metric by Robinson and colleagues (Meyer et al., 2012b). The subject's PCA index was the average of four factors: percentage of time score, number of entries score, probability of approach score, and latency (i.e., first contact) score. Each score was calculated based on $(\mathrm{ST}-\mathrm{GT}) /(\mathrm{ST}+\mathrm{GT})$ in the respective categories. Therefore, each score could range from +1 (complete ST) to -1 (complete GT). For the purposes of this experiment, animals with a positive PCA were considered ST and those with a negative PCA were considered GT.

To ensure reliable ratings, we compiled ratings from 2 observers for a subset of the sessions ( $n=5$ sessions). Using this, we computed interrater reliability using the intraclass coefficient model (Shrout and Fleiss, 1979) and found that our raters were significantly and reliably correlated $(F=$ $8.91, p<0.00001)$. For sessions with multiple raters, we used the average of both scorers in each bin when computing GT and ST scores. For behavioral measures of learning across days, we used only subjects that had usable videos from all $3 \mathrm{~d}$ (day 1,5 , and 10) so that we could use within-subjects measures (control: $n=13$; cocaine: $n=9$ ). However, for interactions between conditioned approach behaviors and DA signaling, we used all subjects that had both scored data and FSCV recordings on the recording day.

Analysis of FSCV recordings was similar to previous reports (Sugam et al., 2014; Saddoris et al., 2015a). Briefly, each subject received electrical stimulation of VTA afferents (frequency: $12-60 \mathrm{~Hz}$, pulses: 1-20) to generate a training set of DA release at the recording location in the NAc. To analyze recorded FSCV data, each subject's training set collected from the recording site was used to convert recorded current during the session chemometrically into DA concentrations (Rodeberg et al., 2015). Concentrations were then aligned to behavioral events to assess DA release dynamics relative to task stimuli. For analysis, we used several factors to assess the relationship between DA and behavior. First, peak DA was the greatest concentration of DA within $1 \mathrm{~s}$ after an event (e.g., CS+, CS-). Second, area under the curve (AUC) was assessed by summating the concentration of DA at each $100 \mathrm{~ms}$ bin for the analysis period minus the AUC for the preceding baseline. For these analyses, subject averages (i.e., the average of each subject's mean DA release for that stimulus) were the data. However, when assessing the effects of ST and GT on behavior, we found that we had few subjects in some groups, so we opted to use a population analysis by using each trial as a datum point rather than the subject average. In all statistical analyses, a mixed-model ANOVA was used to examine DA levels by using the factors of drug (control, cocaine), cue (CS+, CS - ), or reward (reward, post-CS- period), whereas for ST/GT analysis of DA, an additional factor of approach (ST, GT) was used.

Finally, correlations of peak DA were done using other factors such as percentage ST/GT and aspects of self-administration (cocaine intake, drug loading) and included both core and shell recordings. Note that, for these analyses, as with behavior, cue analyses for the CS + trials were performed using subject averages.

All statistical analyses were performed using Statistica version 12 (StatSoft) and GraphPad Prism software.

\section{Results}

\section{Self-administration and Pavlovian discrimination behavior}

Results of self-administration and subsequent extinction appear in Figure 1, $B$ and $C$. During self-administration, thirsty rats readily learned to lever press for either intravenous cocaine (cocaine) or water delivered to a receptacle (control). Rats in the control group more rapidly acquired pressing than rats in the cocaine group (Fig. 1B; ANOVA: group $\times$ day, $F_{(13,273)}=6.03, p<$ $0.0001)$. This increase was apparent as significantly increased responding on days 2 and 3 (Tukey: both $p<0.005$ ), but, by day 5 , there were no differences between press rates within a session (Tukey: cocaine vs control days 5-14, all $p>0.50$ ). Therefore, when the self-administration task was well learned and stable, rats in both groups pressed at similar rates and thus experienced instrumental actions, conditioned stimuli, and reinforcers equivalently.

Next, after a period of self-administration abstinence in their home cages $(30 \mathrm{~d})$, rats were food restricted and trained to perform a Pavlovian discrimination between two visual stimuli (a reinforced CS + and a nonreinforced CS - ) in a novel context. As rats performed this task over $10 \mathrm{~d}$, associative behavior during the task reflected changes in learning (Fig. 2A). Rates of food cup 
A

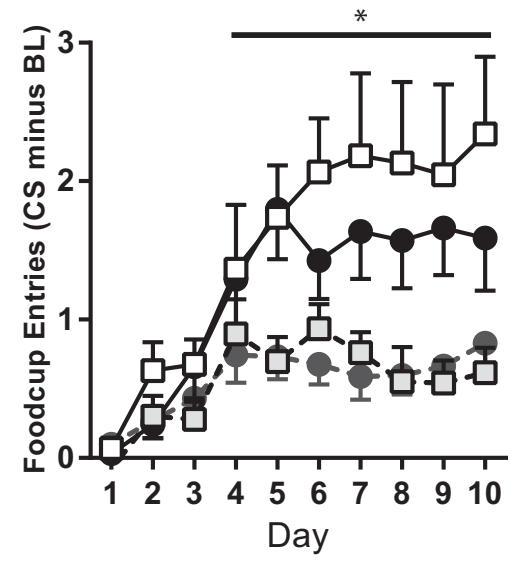

B

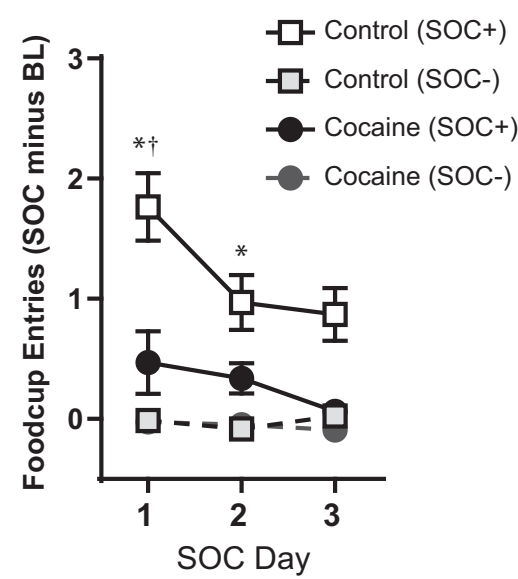

Figure 2. Pavlovian conditioning after 1 month of abstinence from self-administration. First-order sessions were each 83 min, whereas second-order sessions were $3 \mathrm{~h}$ each. $\boldsymbol{A}$, Number of food cup entries during $10 \mathrm{~s}$ cue presentations for the $C S+$ and CS - stimuli (minus the rate during the immediately preceding $10 \mathrm{~s}$ baseline) over $10 \mathrm{~d}$ of F0C in controls $(n=20)$ and cocaine $(n=10)$ rats. $\boldsymbol{B}$, Number of food cup entries during the $10 \mathrm{~s} S O C$ cues during $\mathrm{SOC}$ sessions. ${ }^{*} p<0.05$, CS + vs $C S-$, $\mathrm{SOC}+$ vs $\mathrm{SOC}-$.

entries increased across days (ANOVA: day, $F_{(9,279)}=12.86, p<$ $0.0001)$ and showed increasing abilities to discriminate between the stimuli (ANOVA: cue, $F_{(1,31)}=93.68, p<0.0001$; day $\times$ cue, $\left.F_{(9,279)}=5.51, p<0.0001\right)$, with a significantly greater number of entries during the CS + compared with the CS - on days 5-10 (Tukey; all $p<0.001$ ). However, there was no effect of drug or interactions between drug and other factors (ANOVA; main effect and all interactions, $p>0.50$ ).

Rats were then trained on a second-order schedule where one auditory stimulus $(\mathrm{SOC}+)$ was followed by the $\mathrm{CS}+$ and another (SOC-) was followed by the $\mathrm{CS}-$; neither pair of stimuli were reinforced with food. Consistent with our previous findings (Saddoris and Carelli, 2014), only rats in the control group were able to acquire this discrimination (Fig. $2 B$ ), as indicated by a main effect of drug (i.e., cocaine vs control), $F_{(1,28)}=11.61, p<$ 0.005 , an interaction of drug $\times$ cue (i.e., $\mathrm{SOC}+$ vs SOC -$), F_{(1,28)}$ $=7.09, p=0.01$, and a nearly significant trend for the interaction of drug $\times$ cue $\times$ day (i.e., 3 sessions), $F_{(2,56)}=2.68, p=0.07$. Specifically, rats in the control group showed increased food cup entries during the SOC+ compared with the SOC - on days 1 and 2 of SOC (Tukey: day1, $p=0.006$; day2, $p=0.001$ ), whereas rats in the cocaine group failed to show differences between stimuli on either of these days (Tukey: day1, $p=0.99$; day2, $p=1.0$ ). Furthermore, controls responded at a greater rate than cocaine-SA rats for the SOC+ cue overall (Tukey: $p=0.0007$ ), but did not differ on rates of responding for the SOC- (Tukey: $p=0.34)$.

After self-administration, rats were run in Pavlovian discriminations (see below) before being returned to the selfadministration chamber for extinction. One week after Pavlovian discriminations (i.e., $60 \mathrm{~d}$ of enforced abstinence from the end of self-administration), rats were returned to the original self-administration context, where they were given one self-administration session under extinction conditions (i.e., presses delivered tone/houselight stimuli, but did not result in delivery of either intravenous cocaine or water to the water receptacle; Figure $1 C$ ). An ANOVA indicated that rats varied their extinction press rate based on their drug history [main effect drug, $F_{(1,18)}=5.67, p=0.03$; drug $\times$ extinction (i.e., average SA days $10-14$ vs extinction day), $F_{(1,18)}=4.61, p=0.04$ ]. Although rats in both groups showed similar press rates over the last $5 \mathrm{~d}$ of self-administration (Tukey: $p=0.95$ ), cocaine rats pressed more during extinction than during self-administration (Tukey: $p=0.04$ ) and relative to controls (Tukey: $p=0.01$ ). In contrast, controls showed similar rates of pressing during selfadministration and extinction (Tukey: $p=0.99$ ).

\section{ST and GT behaviors during conditioning}

Next, in the subset of subjects for which we recorded FSCV in the NAc ( $n=14$ control, $n=17$ cocaine; see Fig. 3 for histology), we investigated whether cocaine experience induced changes in the type of the associative approach during task performance by assessing the amount of behavior subjects spent in ST (approaches to the cue light zone) versus GT (approaches to the food cup zone) during trials across training. These PCA behaviors were examined within subjects across days 1,5 , and 10 . However, due to technical issues (i.e., missing or damaged video recordings), some subjects did not contribute data from all 3 sessions and were therefore excluded ( $n=1$ control, $n=8$ cocaine) from this within-subjects analysis. As a result, conditioned approach data were analyzed from 13 control and 9 cocaine subjects.

We first analyzed the percentage of time rats spent performing ST approach behaviors during the cue as learning progressed (Fig. 4A). In general, we found that cocaine subjects showed an overall enhanced ST response relative to controls. Specifically, a multifactor ANOVA using drug (control, cocaine), day (days 1, 5, and 10$)$, phase (BL, early cue, late cue), and cue (CS+, CS - ) indicated both a main effect of drug, $F_{(1,20)}=5.19, p=0.03$, and an interaction of drug with all other factors, drug $\times$ day $\times$ phase $\times$ cue, $F_{(4,80)}=4.51, p=0.002$. This interaction indicated that all rats displayed similar amounts of ST to the cue on day 1 (Tukey: cocaine vs control, $\mathrm{CS}+, p=1.0$; $\mathrm{CS}-, p=1.0$ ) and that none of these ST levels during either the early or late phase of cue presentation was different from BL (Tukey: all $p=1.0$ ). Therefore, the different visual cues had no intrinsic motivational value that may have been generalized from previous self-administration cues for either group.

However, on day 5, cocaine animals showed a significant increase in ST to the CS+ during the early and late phases of cue presentation (Tukey: day 1 vs day 5 , early cue: $p=0.0002$; late cue: $p=0.0002$ ), but no increase in ST for the CS - cue (Tukey: both $p>0.31$ ), resulting in significantly greater ST for the CS+ than the CS - in the late phase (Tukey: $p=0.02$; early phase, $p=$ $0.17)$. Indeed, ST for the CS + was significantly greater than BL in 
both the early and late cue phase (Tukey: both $p=0.0002$ ), whereas ST for the CSwas only greater than $\mathrm{BL}$ in the late phase (Tukey: $p=0.0007$; early phase, $p=$ $0.45)$. In contrast, controls showed the opposite pattern of ST. There was no change in the amount of ST to the CS+ cue during either the early or late cue phases (Tukey: both $p>0.18$ ), but there was instead a significant increase in ST to the CS - cue during the late cue phase (Tukey: $p=0.02$; early phase, $p=0.75$ ), resulting in significantly greater ST to the $\mathrm{CS}$ - than the CS + cue during the late cue phase on day 5 (Tukey: $p=0.04$; early phase, $p=1.0)$. Here, ST for the CS+ was not different from BL during either phase (Tukey: both $p>0.09$ ), whereas ST for the CS- was greater than $\mathrm{BL}$ in both phases (Tukey: both $p<0.05$ ). Finally, on this intermediate conditioning session, cocaine rats showed significantly elevated ST to the CS + relative to controls during the late cue phase (Tukey: $p=0.001$; early phase, $p=0.67$ ), whereas there were no differences in ST for the CS- cue during any phase (Tukey: all $p=1.0$ ).

On the final day of conditioning, day 10 , we saw much the same pattern of ST behavior. In cocaine animals, ST responding was significantly greater than BL in both the early and late cue phases for the CS + (Tukey: both $p=0.0002$ ), but not the CS - (Tukey: both $p>0.95$ ), resulting in significantly greater ST for the CS+ than the CS - in both the early and late phases of cue presentation (Tukey: both $p=0.0002$ ). In contrast, controls showed ST to the cues that was at BL levels (Tukey: all $p>0.19$ ) and did not distinguish between $\mathrm{CS}+$ and CS - cues at any phase (Tukey: all $p>0.35$ ). Therefore, ST for the CS + was significantly greater in cocaine than controls during both the early and late cue phases (Tukey: both $p<0.008$ ), whereas there were no differences in ST between groups to the CS - (Tukey: early and late, $p>0.95$ ). However, for neither group did the amount of ST change statistically between days 5 and 10 (Tukey: all $p>0.96$ ), suggesting that ST rates, particularly for the $\mathrm{CS}+$, were stable relatively early in conditioning.

For GT behaviors (Fig. $4 B$ ), we found almost exactly the inverse pattern of conditioned approach as we did for ST. An ANOVA using the same factors as for ST revealed significant interactions between drug $\times$ day $\times$ phase, $F_{(4,80)}=3.38, p=0.01$, drug $\times$ cue $\times$ phase, $F_{(2,40)}=5.18, p=0.01$, and a nearly significant interaction of drug $\times$ day $\times$ cue $\times$ phase, $F_{(4,80)}=2.37, p=0.059$. Here, controls showed more robust GT than cocaine subjects across days. Although there were no differences in in GT rates between groups for any of the stimuli or phases on day 1 (Tukey: all $p=1.0$ ), control rats showed a significant increase in GT approach from day 1 to day 5 for both the $\mathrm{CS}+$ cue and CS - cue (Tukey: both early and late phases, all $p=$ $0.0002)$. From day 5 to day 10, GT during the CS + increased during the early phase (Tukey: $p=0.0002$; late phase, $p=0.71$ ) and decreased during the CS - in both phases (Tukey: both $p=0.0002$ ). Therefore, GT during the CS+ was significantly greater than the shell placements.
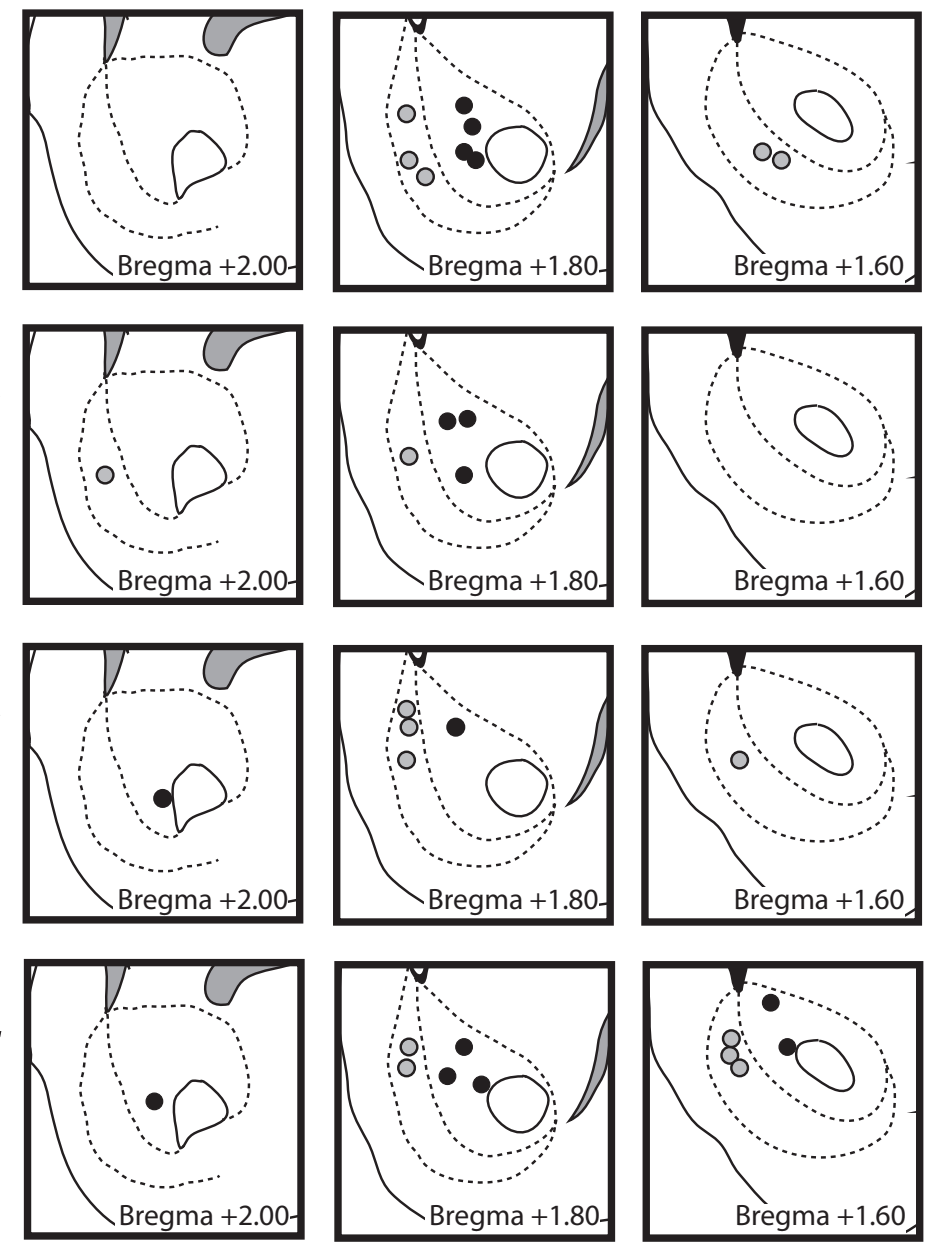

Figure 3. Histological electrode placement for valid FSCV recordings. Black circles indicate core placements; gray circles indicate

CS - on both day 5 and on day 10 (Tukey: both early and late phases, $p=0.0002)$.

Cocaine animals showed a significantly diminished rate of GT responding compared with controls. Cocaine rats saw increases in GT behavior between day 1 and day 5 only during the late phase of the cue (Tukey: $p=0.0002$; early phase, $p=0.99$ ) and not at all between day 5 and day 10 (Tukey: $p>0.79$, both phases). Likewise, cocaine rats only showed increased GT behavior for the CS+ over the CS - on day 10 during the late cue phase (Tukey: $p=0.0002$; early phase, $p=0.85$ ), but not at any point on day 5 (Tukey: $p>0.28$ both phases). Indeed, GT responding on both day 5 and day 10 was only greater than BL during the late phase (Tukey: both $p=0.0002$ ) and not during the early phase (Tukey: day $5, p=0.09$; day $10, p=$ 0.99). As a result, GT behavior in controls was significantly greater during the CS + than cocaine rats on both day 5 (Tukey: late phase, $p=0.002$; early phase: $p=0.12$ ) and day 10 (Tukey: late phase: $p=$ 0.013 ; early phase, $p=0.83$ ). In contrast, there were no differences in GT behavior for the CS - cue during any phase on any day (Tukey: all $p>0.92$ ).

Despite these wide disparities in percentage of time in GT and ST, the total amount of behavior (sum of time approaching either stimulus) performed by animals in each group during the cue was essentially the same (Fig. 4C). Looking at the summated ST and GT behavior for each subject with a multifactor ANOVA (same factors as for ST and GT analysis above), there was no main effect of drug, $F_{(1,20)}=0.39, p=0.54$, or any interaction of drug with 

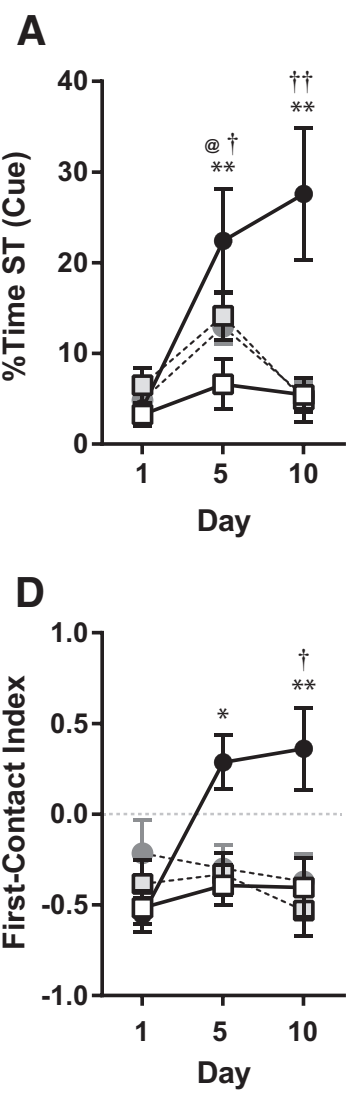

B

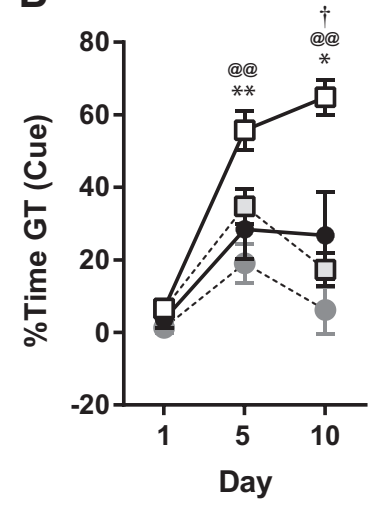

E

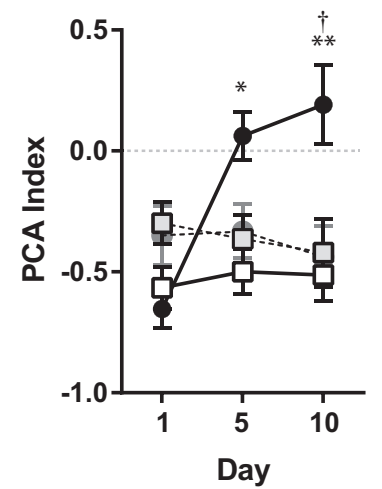

C

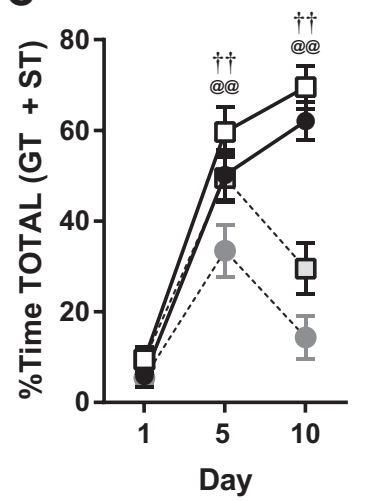

$\mathbf{F}$

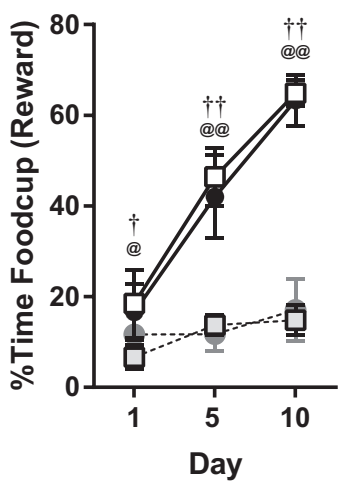

Figure 4. Development of differential PCA behaviors across FOC sessions in controls $(n=13)$ and cocaine $(n=9)$ subjects. The percentage of time the rats spent either in ST (A) or GT ( $\boldsymbol{B})$ during the cue presentations varied by drug experience. $\boldsymbol{C}$, Total amount of conditioned approach behavior (GT plus ST) during cues was the same between groups. $\boldsymbol{D}$, The first contact index indicates the proportion of times the rats made their first response to either the cue light $(+1)$ or the food cup $(-1)$ during cue presentations. $\boldsymbol{E}$, PCA index (the averaged indices of percentage of time, number of entries, probability of entry, and first contact for the cue and goal) during cue presentations. $F$, Percentage time in the goal cup in the $5 \mathrm{simmediately} \mathrm{after} \mathrm{reward} \mathrm{delivery} \mathrm{did} \mathrm{not} \mathrm{differ} \mathrm{between}$ groups. ${ }^{*} p<0.05,{ }^{* *} p<0.01$, control vs cocaine; $\uparrow p<0.05$, $†+p<0.01$, cocaine CS + vs cocaine CS - ; $@ p<0.05$, @ $p<0.01$, control CS + vs control CS -

cue or day (all ANOVA interactions, $p>0.23$ ). Indeed, using the same post hoc comparisons as above, we found no differences between drug groups for any cue on any day or during any phase of the cue presentation (Tukey: all $p>0.92$ ). Given this equivalency, these data suggest that both groups of animals were equally able to perform the Pavlovian discrimination, but the manner in which they deployed their conditioned approach behavior differed based on drug experience.

We also found that it was not just the amount of time spent with the different stimuli that varied, but the speed with which animals approached the different stimuli. The first contact index (i.e., if first contact [entry into the cue zone] was with the cue light after trial onset, it was scored as a +1 , whereas if first contact was with the food cup zone, the trial was scored as a -1 ) showed a similar pattern as the percentage of time measure for ST (Fig. $4 D$ ). An ANOVA using drug, day, and cue type as factors indicated a significant main effect of drug, $F_{(1,20)}=8.98, p=0.007$, and a significant interaction of drug $\times$ cue $\times$ day, $F_{(2,40)}=5.46$, $p=0.008$. This effect was carried by a strong shift in the firstcontact response bias in the cocaine group. On day 1 , all subjects showed a strong bias toward responding first to the food cup regardless of drug background (Tukey: cocaine vs control, CS+, $p=1.0$; CS,$- p=0.99$ ). By day 5 , cocaine subjects shifted their responding first to the cue light during the CS+ (Tukey: day 1 vs day $5, p=0.004$ ), but not the CS- (Tukey: $p=1.0$ ), whereas controls showed no change in their first-contact response from day 1 to day 5 for either cue (Tukey: both CS + and CS,$- p=$
0.99). However, both groups' first-contact responses were stable between day 5 and day 10 (Tukey: day 5 vs day 10, all cues, $p>$ $0.93)$. Therefore, the first-contact responding was significantly biased in the cue direction (i.e., more positive) for cocaine animals compared with controls for the CS+ on day 5 (Tukey: $p=$ 0.04 ) and day 10 (Tukey: $p=0.002$ ), whereas CS - responding was not different between groups on any day (Tukey: all $p>0.99$ ) and was more food cup biased (i.e., more negative).

Putting these measures together using a modified version of the PCA index (Meyer et al., 2012b), an ANOVA using drug, day, and cue as factors indicated a similar result as above (Fig. $4 E$ ). There was a main effect of drug, $F_{(1,20)}=7.6, p=0.01$, and an interaction of drug $\times$ day $\times$ cue, $F_{(2,40)}=3.78, p=0.03$. Cocaine rats show a significantly more ST-biased PCA score compared with controls, but only for the CS+ cue. On day 1 , both groups showed similar PCA scores (biased toward the food cup; Tukey: $p=1.0$ for both CS + and CS - ), whereas cocaine rats showed more ST bias during the CS + than controls on day 5 (Tukey: $p=$ 0.02 ) and day 10 (Tukey: $p=0.001$ ). Indeed, there was significantly enhanced PCA bias for the CS + versus the CS - on day 10 in cocaine animals (Tukey: $p=0.01$ ), but not in controls (Tukey: $p=0.99)$. There were no differences in PCA scores for the CSstimuli between groups on any day (Tukey: all $p=1.0$ ).

Given the robust differences in cue performance, it was important to make certain that the rats were equally motivated to obtain the food once delivered (Fig. 4F). Looking at the percentage of time in the food cup during the first $5 \mathrm{~s}$ after reward 
A

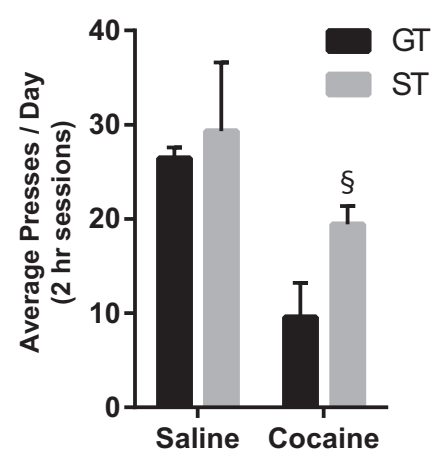

B

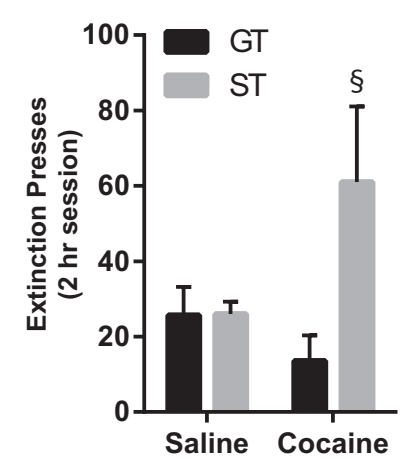

C

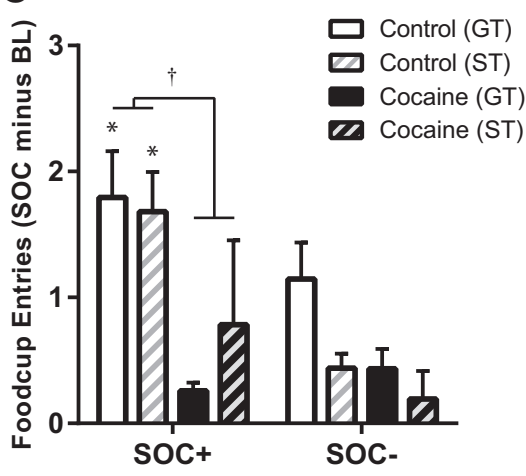

Figure 5. Interactions of identified first-order ST and GT phenotype with self-administration behavior and higher-order conditioning. Cocaine rats that showed greater ST behaviors during FOC were found to have self-administered cocaine at a higher rate $(\boldsymbol{A})$ and to have emitted more extinction responses $(\boldsymbol{B})$. $\boldsymbol{C}$, Individual differences in ST or GT behaviors during FOC had no effect on the ability to perform the SOC discriminations; both GT and ST controls were able to discriminate the stimuli, whereas ST and GT cocaine subjects were both impaired at the discrimination. $\$ p<0.05$, GT vs ST; ${ }^{*} p<0.05, \mathrm{SOC}+$ vs SOC $-; \uparrow p<0.05$, control vs cocaine.

delivery, a factorial ANOVA using drug, day, and reward (food delivery vs equivalent post-CS - period) indicated a main effect of day, $F_{(2,40)}=39.92, p<0.00001$, reward, $F_{(1,20)}=193.86, p<$ 0.00001 , and day $\times$ reward, $F_{(2,40)}=34.65, p<0.00001$, but no main effect of drug or any interaction of drug with any other factors (all $p>0.31$ ). Post hoc comparisons indicated that rats increased food cup time during the reward from day 1 to day 5 (Tukey: both control and cocaine, $p<0.001$ ) and again from day 5 to day 10 (Tukey: both control and cocaine, $p<0.01$ ), whereas there was no difference in food cup time during the post-CSacross days (all $p>0.76$ ). Therefore, there was more time spent in the food cup after reward delivery than during the post-CSperiod on day 5 (Tukey: control, $p<0.001$, cocaine, $p<0.002$ ) and on day 10 (Tukey: control and cocaine, $p<0.0001$ ). There were no differences between drug groups for either outcome on any day (Tukey: all $p=1.0$ ).

\section{Individual differences in conditioned approach phenotype and other behaviors}

Given the dramatic role that cocaine experience played in altering conditioned responding, we next wanted to know whether individual differences in drug intake differentially altered other aspects of motivated behavior. Based on PCA scores relative to the $\mathrm{CS}+$ cue from scored behavior on day 10 (thus including some subjects that were excluded above due to missing data from days 1 and 5), we identified 5 ST $($ PCA $>0)$ and 15 GT $($ PCA $<0)$ in the control group and 11 ST and 4 GT in the cocaine group, a distribution that was significantly different $\left(\chi^{2}=6.239, p=0.0125\right)$. Using these classifications, we then investigated whether GT and ST rats displayed differential behavior during self-administration. In cocaine rats, those that were identified as ST during FOC were found to have pressed at a higher rate (and thus had more total cocaine intake over the course of the experiment) than those that displayed GT during FOC, $t_{(11)}=2.27, p=0.04$ (Fig. $5 A$ ). In contrast, ST and GT controls showed equivalent pressing rate during the earlier water self-administration, $t_{(13)}=0.55, p=0.59$. Likewise, cocaine ST rats were significantly more likely to show significantly elevated rates of extinction pressing than cocaine GT rats, $t_{(9)}$ $=2.76, p=0.02$, whereas control ST and GT rats showed similar rates of extinction pressing, $t_{(12)}=0.03, p=0.98$ (Fig. 5B).

However, ST and GT status during FOC had no effect on subsequent SOC (Fig. 5C). For the first $2 \mathrm{~d}$ of SOC, there was a significant interaction between SOC cue type (baseline, SOC,+ SOC - ) and drug, $F_{(2,112)}=5.17, p=0.0072$, which supported our earlier observation that controls showed significant increases in food cup approaches for the SOC+ relative to the baseline and SOC-, as well compared with cocaine SOC + , whereas cocaine subjects showed no differences between any of the stimuli. However, there was no effect of PCA type (ST vs GT), $F_{(1,56)}=1.50, p=0.23$, or any interaction of PCA by any other factor. Indeed, planned comparisons between food cup approaches during the SOC + and SOC-cues indicated that rats showed greater approach during the SOC+ than the SOC - in both control ST (Tukey: $p=0.027$ ) and control GT (Tukey: $p=0.0001$ ) subjects, but not in the cocaine ST (Tukey: $p=0.98$ ) or cocaine GT (Tukey: $p=0.59$ ) subjects. Furthermore, there was no reliable difference in food cup approach during the SOC + between ST and GT rats in either controls (Tukey: $p=0.71$ ) or cocaine rats (Tukey: $p=$ 0.97). Therefore, cocaine experience appeared to selectively alter the shape of the associative response during FOC, but to more generally abolish the ability to learn second-order associations.

\section{FSCV during FOC}

After $9 \mathrm{~d}$ of FOC and with the discrimination well learned, realtime DA release patterns were measured in the NAc core (control, $n=7$; cocaine, $n=8$ ) or shell (control: $n=7$; cocaine: $n=9$ ) using FSCV while rats performed the Pavlovian task.

In the NAc core (Fig. 6), phasic DA release patterns in controls tracked information about the Pavlovian stimuli (Fig. 6A, C). DA release increased rapidly after cue onset, was greater for $\mathrm{CS}+$ than $\mathrm{CS}-$, and then returned to low levels by the time of reward receipt. In contrast, cocaine subjects showed a different pattern (Fig. 6B,D), with a much more blunted response to the cues and a large DA release event at reward delivery. We quantified these patterns by first looking at average DA release $1 \mathrm{~s}$ after cue onset (Fig. 6E). A two-way ANOVA indicated that there was both a main effect of drug, $F_{(1,13)}=6.97, p=0.02$, and an interaction of drug $\times$ cue, $F_{(1,13)}=5.71, p=0.03$, which indicated that control DA successfully discriminated between CS + and CS - cues (Tukey: $p=0.02$ ), whereas cocaine DA did not (Tukey: $p=0.99$ ). Furthermore, DA release for the CS+ cue was greater in controls than in cocaine subjects (Tukey: $p=0.01$ ), but did not differ for the CS - (Tukey: $p=0.61$ ). 
A

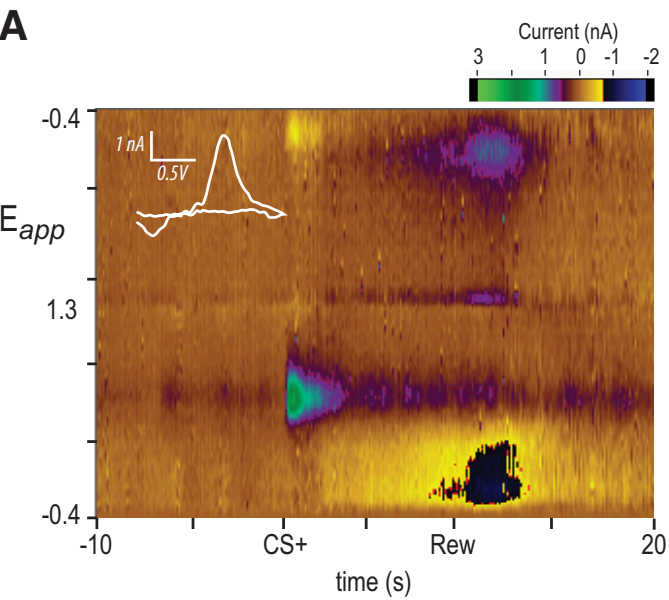

C

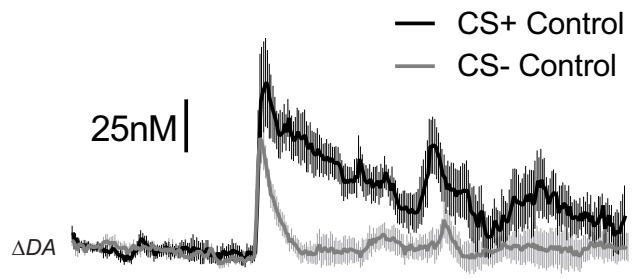

$-10$

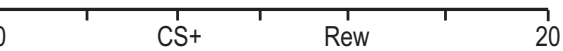

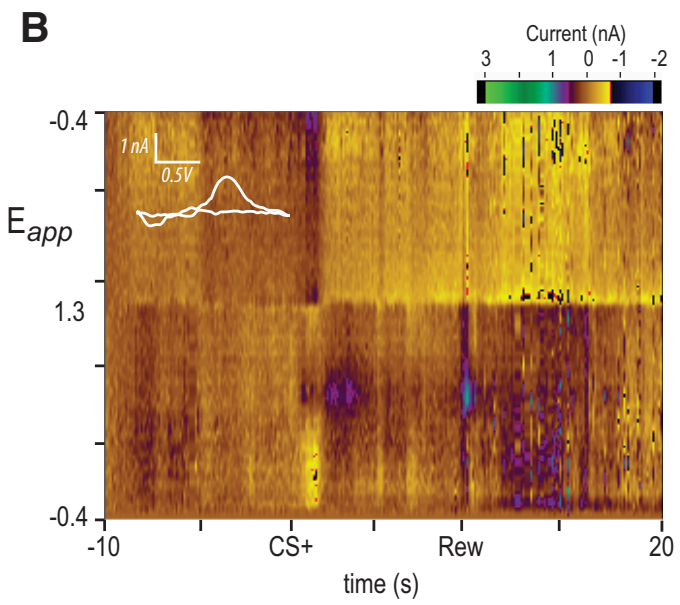

D

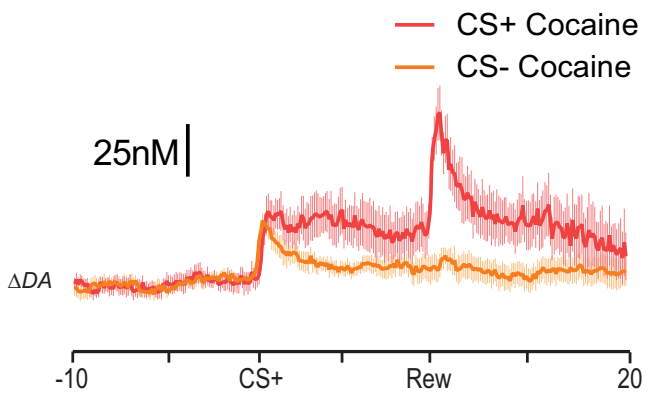

E

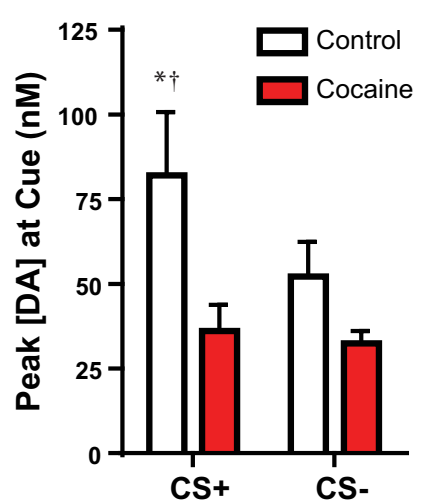

$\mathbf{F}$

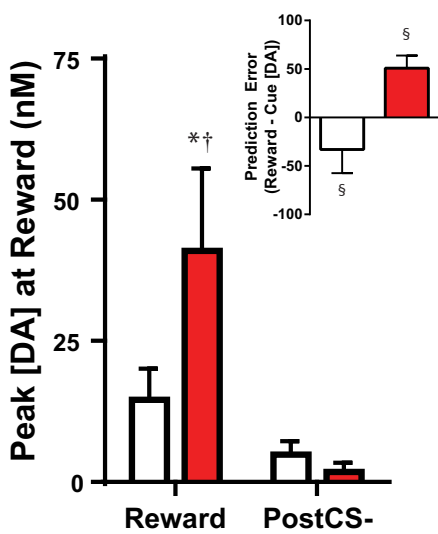

G

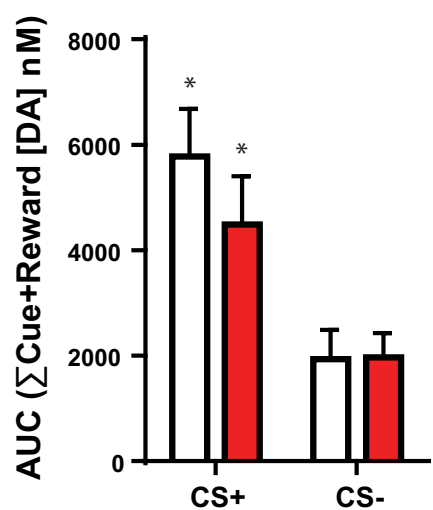

Figure 6. Phasic DA recordings from the NAc core during a well learned first-order Pavlovian discrimination in controls $(n=8)$ and cocaine-experienced subjects ( $n=8$ ). Representative color plots of single CS + trials from a control $(\boldsymbol{A})$ and a cocaine-experienced $(\boldsymbol{B})$ subject. Inset in top left corner shows the cyclic voltammogram (current vs voltage; $(\mathrm{V})$ at the oxidation potential for DA from a representative transient release event on the color plot. Subject averages for controls $(\boldsymbol{C})$ and cocaine $(\boldsymbol{D})$ rats in the task showing real-time concentrations of DA aligned to the $C S+$ and $C S-$ trials. $E$, Peak DA release immediately after cue onset shows decreased and nonspecific DA release in cocaine rats (red) that was reliably decreased relative to controls (white) during the $C S+$, but not CS - . F, Peak DA release during the reward period was selectively enhanced for the reward receipt in cocaine subjects relative to controls. Inset, Average difference between $C S+$ and reward DA was significantly above zero in controls and below zero in cocaine subjects. G, Total volume of DA release (summed concentration of DA during the $10 \mathrm{~s}$ cue period plus $2 \mathrm{~s}$ reward period) was greater for $C S+$ than $C S-$ trials, but did not vary between cocaine and controls. ${ }^{*} p<0.05$, CS + vs $C S-$; $\nmid p<0.05$, control vs cocaine, $\$ p<0.05$ vs baseline.

In contrast to cue encoding, cocaine subjects showed a bias toward greater DA release during rewards (Fig. $4 F$ ). Compared with the pretrial baseline, a factorial ANOVA indicated a significant interaction between drug $\times$ phase (baseline vs reward period) $\times$ reward (food vs post-CS - ), $F_{(1,13)}=4.87, p=0.04$. This result was due to cocaine animals releasing significantly more DA during the reward than during the nonrewarded post-CSperiod (Tukey: $p=0.0002$ ); there was no such difference between reward types in controls (Tukey: $p=0.11$ ). Further, DA at reward was significantly enhanced in cocaine compared with controls (Tukey: $p=0.01$ ), though DA to the post-CS - did not differ between groups (Tukey: $p=0.99$ ).

This asymmetry in cue and reward encoding was then quantified by subtracting peak DA at reward from peak DA during the CS+ (Fig. 6F, inset). DA at the cue minus DA at the reward was significantly different between the groups, $t_{(13)}=3.15, p=0.008$; 
A

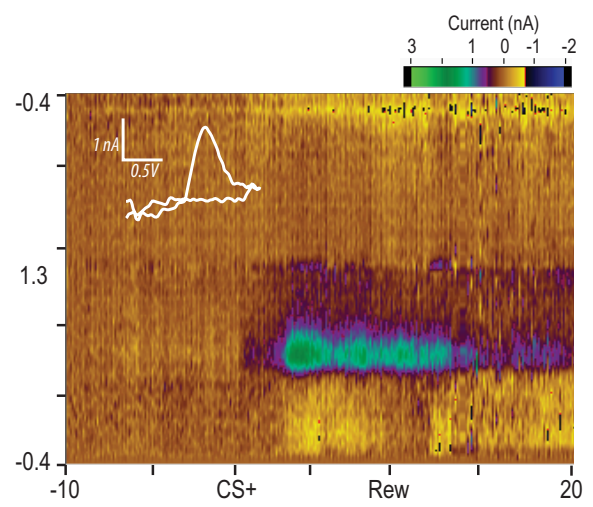

C

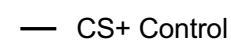

- CS- Control

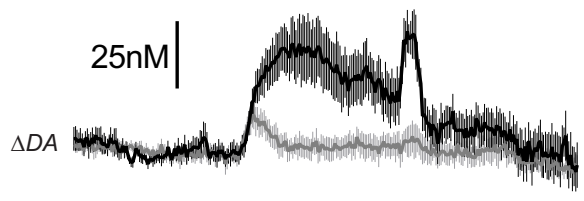

B

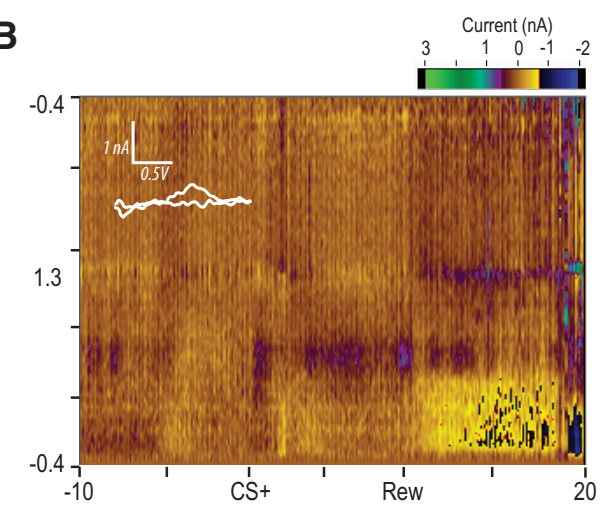

D
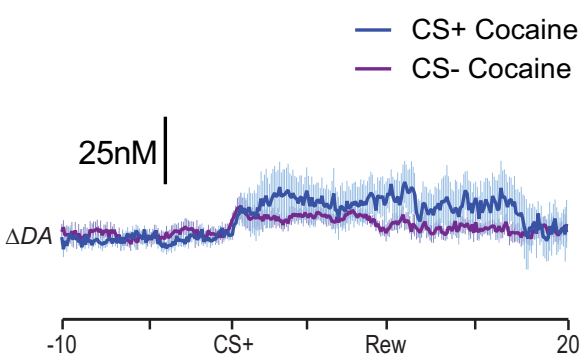

E

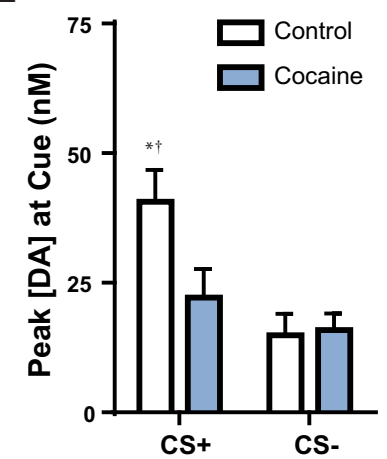

$\mathbf{F}$

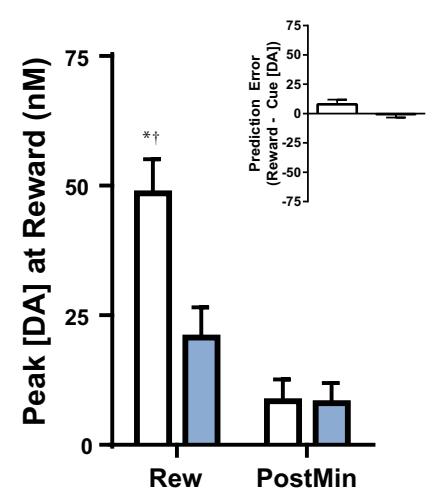

G

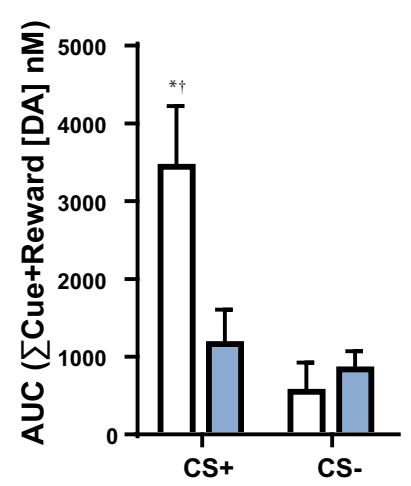

Figure 7. Phasic DA recordings from the NAc shell during a well learned first-order Pavlovian discrimination in controls $(n=7)$ and cocaine-experienced subjects $(n=9)$. Representative color plots of single CS + trials from a control $(\boldsymbol{A})$ and a cocaine-experienced $(\boldsymbol{B})$ subject. Inset in top left corner shows the CV from a representative transient release event on the color plot. Subject averages for controls $(\boldsymbol{C})$ and cocaine $(\boldsymbol{D})$ rats in the task show real-time concentrations of $D A$ aligned to the $C S+$ and $C S-$ trials. $\boldsymbol{E}$, Peak DA release immediately after cue onset show decreased and nonspecific DA release in cocaine rats (blue) that was reliably decreased relative to controls (white) during the $C S+$, but not $C S-$. $F$, Peak DA release during the reward period was selectively enhanced for the reward receipt in controls relative to cocaine subjects. Inset, Average difference between $C S+$ and reward DA was similar to zero in both drug groups. $G$, Total volume of DA release was greater for $C S+$ than $C S-$ trials only in controls. ${ }^{*} p<0.05, C S+$ vs $C S-; \dagger p<0.05$, control vs cocaine.

this difference was significantly greater than chance (i.e., cue biased) in controls, $t_{(6)}=4.15, p=0.006$, but significantly less than chance (i.e., reward biased) in cocaine subjects, $t_{(7)}=-8.51, p<$ 0.0001 .

Next we examined the cumulative DA release (AUC) for the cue and reward periods (Fig. 6G). This analysis summates the DA concentration in each $100 \mathrm{~ms}$ bin across the $10 \mathrm{~s}$ cue period and $2 \mathrm{~s}$ of the reward period and captures slower DA release kinetics that may not be apparent from peak values at cue and reward onset. Surprisingly, there was no effect of drug, $F_{(1,13)}=0.55, p=$ 0.47 , or interaction of drug $\times$ cue, $F_{(1,13)}=1.91, p=0.29$; post hoc tests indicated that there was more total DA released for the $\mathrm{CS}+/$ reward than the CS-/post-CS - trials in both controls (Tukey: $p=0.004$ ) and cocaine subjects (Tukey: $p=0.04$ ), but that there was no difference in total DA between groups during the CS+/reward (Tukey: $p=0.61$ ) or CS-/post-CS - stimuli (Tukey: $p=0.99$ ).

The NAc shell showed a different pattern of both encoding and sensitivity to cocaine exposure. Example traces show representative trials in controls (Fig. 7A) and cocaine subjects (Fig. 7B) for the CS + . DA release patterns in the shell of controls generally tracked differences in associative cue value for the different stimuli, with greater DA for both the cue and reward receipt during the CS+ trials than in the CS - (Fig. 7C). In contrast, shell DA release in cocaine subjects was strongly attenuated, and showed little difference in encoding between any stimuli (Fig. 7D). To quantify this, a two-way ANOVA compared peak baseline subtracted DA after the cue for the stimuli by group (Fig. 7E). Here, 
A

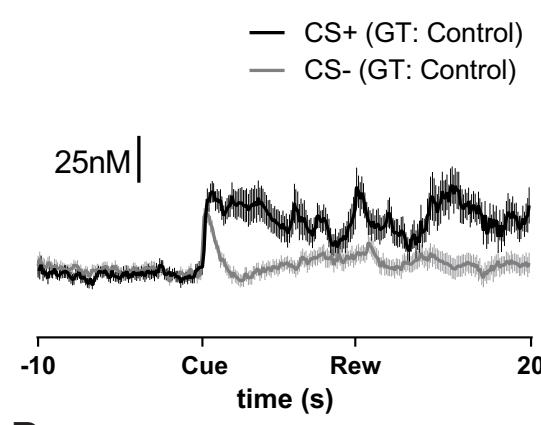

D
B

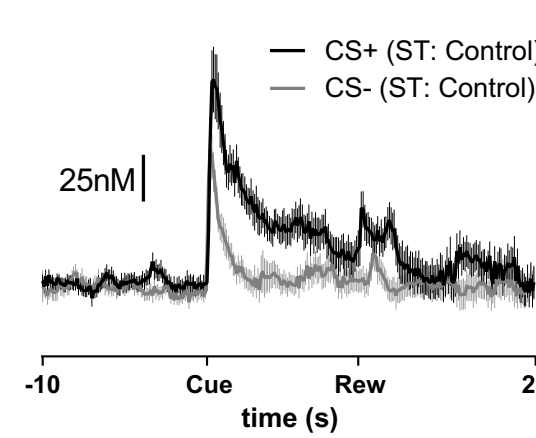

$E$

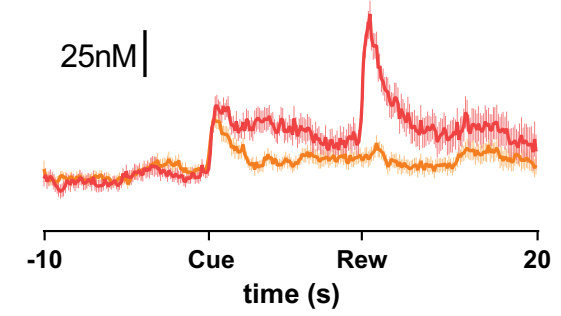

C

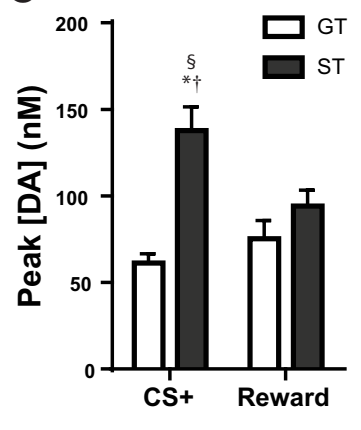

$\mathbf{F}$

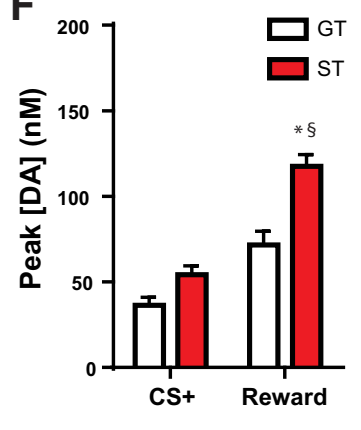

Figure 8. NAccore population DA concentrations (i.e., average of trials) for subjects classified as either ST (controls: $n=56$; cocaine: $n=84$ ) or GT (controls: $n=56$; cocaine: $n=28$ ). In controls, the $C S+$ cue generally elicited more DA release than the $C S-$ in both GT $(\boldsymbol{A})$ and ST $(\boldsymbol{B})$ subjects. $\boldsymbol{C}$, Peak DA for controls showed greater DA at the CS + in ST than GT, but similar DA at the reward. Cocaine-experienced animals showed less discrimination between cues in both the GT $(\boldsymbol{D})$ and ST $(\boldsymbol{E})$ groups. $\boldsymbol{F}$, Peak DA in cocaine subjects did not differ at the cue, but did differ at the reward between ST and GT. $\S p<0.05$, cue vs reward; * $p<0.05$, ST vs GT; $\uparrow p<0.05$, control vs cocaine.

a significant interaction of drug $\times$ cue, $F_{(1,13)}=11.85, p=0.004$, indicated that more DA was released after the CS + than the CSin controls (Tukey: $p=0.0006$ ), whereas there was no such difference in cocaine subjects (Tukey: $p=0.77$ ). Although there was greater DA release during the $\mathrm{CS}+$ for controls relative to cocaine subjects (Tukey: $p=0.008$ ), DA for the CS - was similar between groups (Tukey: $p=0.99$ ).

Next, we quantified reward-related DA release. Unlike in the core, DA release in the shell closely tracked the reward receipt in controls, but less so in cocaine animals (Fig. 7F). A two-way ANOVA found both a main effect of drug, $F_{(1,13)}=6.11, p=$ 0.03 , and an interaction of drug $\times$ reward, $F_{(1,13)}=8.52, p=$ 0.01 , which indicated that reward-evoked DA release in controls was greater than the corresponding post-CS - period (Tukey: $p=0.005)$, whereas this difference did not exist for cocaine subjects (Tukey: $p=0.25$ ). Indeed, there was greater DA release for the reward in controls than for cocaine subjects (Tukey: $p=$ $0.005)$, but similar amounts of DA for the post-CS - period for both groups (Tukey: $p=0.99$ ). Therefore, unlike in the core, there was no reliable difference between cue-evoked and rewardevoked DA in either group (Fig. $7 F$, inset).

Finally, the total amount of DA release in the shell (AUC) during the cue and reward was strikingly different from what was seen in the core (Fig. $7 G$ ). Although there was no main effect of drug, $F_{(1,13)}=2.87, p=0.11$, there was an interaction of drug $\times$ cue/reward, $F_{(1,13)}=13.56, p=0.003$, which indicated greater DA release in controls for the $\mathrm{CS}+/$ reward trials than in the CS $-/$ post-CS - trials (Tukey: $p=0.0006$ ) or in $\mathrm{CS}+/$ reward trials in cocaine subjects (Tukey: $p=0.02$ ). There was no difference in the cocaine group between $\mathrm{CS}+/$ reward and CS -/post-CS - trials (Tukey: $p=0.90$ ). Therefore, cocaine experience decreased associative NAc shell DA release in general, unlike in the core, where changes in release patterns after cocaine were stimulus specific.

\section{DA release in $\mathrm{GT}$ and $\mathrm{ST}$}

Previous work has suggested that differences in patterned DA release are associated with GT and ST behaviors (Flagel et al., 2011; Saunders and Robinson, 2012). Specifically, in ST, DA increases for the predictive and "salient" cue while decreasing for the predicted reward, whereas in GT, DA remains similar for the cue and reward. Although this has been demonstrated in the NAc core, it is unknown whether this is specific to the subregion or if it is a general property of the mesolimbic DA system. To test this, we analyzed trials from subjects in the NAc core and shell in cocaine and control groups based on whether the subject generally showed ST or GT behavior, as determined from their PCA index.

In the NAc core, controls (Fig. $8 A-C$ ) showed a pattern of DA peak release markedly consistent with previous reports (Flagel et al., 2011), but this changed with drug experience. A 3-way ANOVA indicated a significant effect of drug, $F_{(1,149)}=10.95$, $p=0.001$, and an interaction of drug $\times$ approach (i.e., ST vs GT $) \times$ event (i.e., cue vs reward), $F_{(1,149)}=10.83, p=0.001$. Specifically, in GT controls, there was no difference between CS+ and reward-evoked DA (Tukey: $p=0.96$ ), whereas in ST controls, the CS+ elicited significantly greater DA than the reward (Tukey: $p=0.005$ ). Therefore, DA at the CS+ was significantly greater in ST than GT (Tukey: $p<0.0001$ ), whereas there was no difference in DA between ST and GT at the reward (Tukey: $p=$ 0.81; Fig. $8 C$ ). In contrast, cocaine subjects failed to show this pattern (Fig. $8 D-F$ ). GT cocaine subjects failed to show differences in peak DA release between CS+ and reward (Fig. 8F; Tukey: $p=0.38$ ), whereas ST cocaine subjects showed a significant difference due to greater DA at the reward than the CS + cue (Tukey: $p<0.0001$ ). Therefore, ST and GT cocaine subjects did not show differences at the time of the CS+ (Tukey: $p=0.90$ ), but there was reliably more DA at the reward for ST than GT 
A
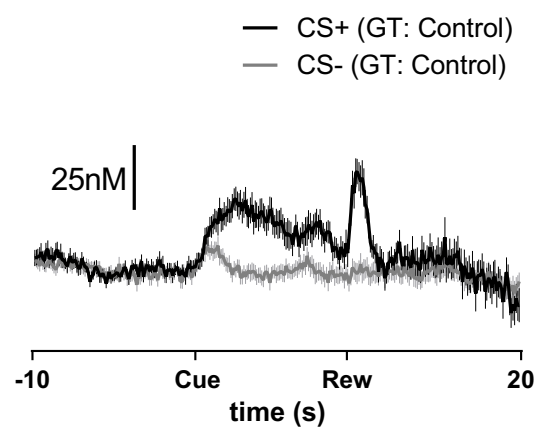

D
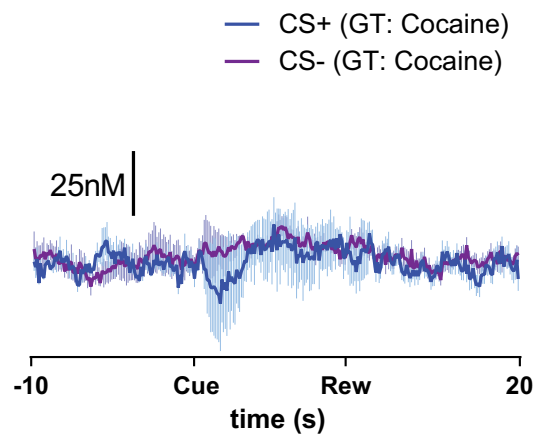

B

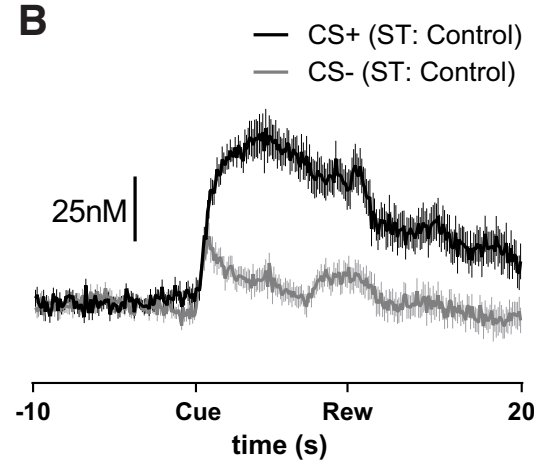

E
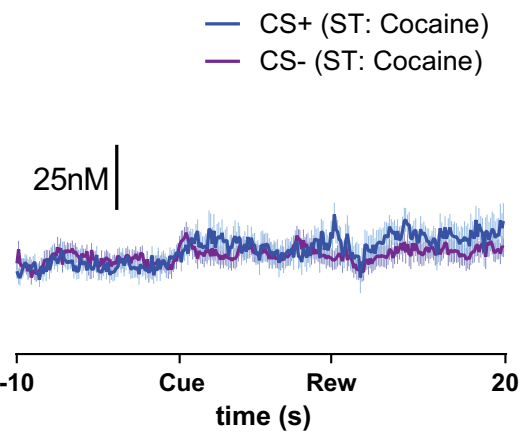

C

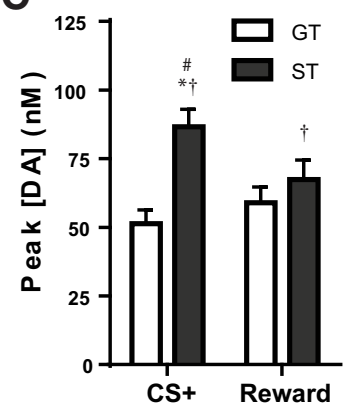

$\mathbf{F}$

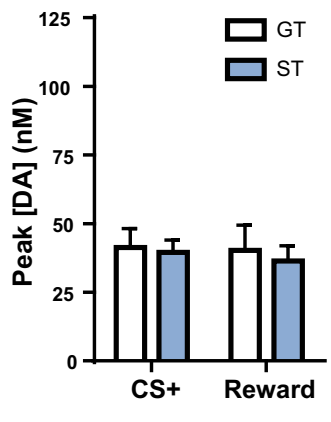

Figure 9. NAc shell population DA concentrations (i.e., average of trials) for ST (controls: $n=28 ;$ cocaine: $n=70$ ) and GT subjects (controls: $n=70$; cocaine: $n=56$ ). In controls, the CS + cue generally elicited more DA release than the $C S-$ in both GT $(\boldsymbol{A})$ and ST $(\boldsymbol{B})$ subjects. $\boldsymbol{C}$, Peak DA for controls showed greater DA at the CS+ in ST than GT, but similar DA at the reward. Cocaine-experienced animals showed no discrimination between cues in both the GT (D) and ST (E) groups. $\boldsymbol{F}$, Peak DA in cocaine subjects did not differ at the cue or reward between ST and GT.\#p $<$ 0.08 , cue vs reward; ${ }^{*} p<0.05$, ST vs GT; $\nmid p<0.05$, control vs cocaine.

subjects (Tukey: $p=0.02$ ). Finally, cocaine experience selectively impaired peak DA release in ST, but not GT rats. During the CS+ cue, control ST rats released significantly more DA than cocaine ST rats (Tukey: $p<0.0001$ ), whereas there was no difference in DA release at the CS + for GT subjects (Tukey: $p=0.72$ ). However, cocaine experience did not modulate DA release at reward in either ST (Tukey: $p=0.42$ ) or GT (Tukey: $p=1.0$ ) subjects.

The NAc shell showed a similar pattern of peak DA release as the core in controls (Fig. 9). In the shell, a 3-way ANOVA indicated a main effect of drug, $F_{(1,131)}=20.71, p<0.0001$, a significant interaction of drug $\times$ approach, $F_{(1,131)}=3.99, p=0.048$, and a trend toward significance for an interaction of drug $X$ approach $\times$ event, $F_{(1,131)}=2.76, p=0.09$. Specifically, in GT controls, there was no difference between $\mathrm{CS}+$ and reward (Tukey: $p=0.90$ ), whereas in ST controls, there was a trend toward greater DA at the CS + than reward (Tukey: $p=0.08$ ). Directly comparing these groups, there was significantly greater peak DA in ST controls than GT controls (Tukey: $p=0.003$ ), whereas there was no difference in reward between ST and GT (Tukey: $p=0.99$ ). In contrast, there was no difference between $\mathrm{CS}+$ and reward in either GT cocaine (Tukey: $p=1.0$ ) or ST cocaine (Tukey: $p=0.84$ ) subjects, nor did ST and GT cocaine subjects differ in peak DA signaling for either the CS+ (Tukey: $p=1.0$ ) or reward (Tukey: $p=1.0$ ). Comparing the effects of cocaine on these measures, ST controls showed significantly greater DA release than ST cocaine subjects for both the CS+ (Tukey: $p=0.0001$ ) and the reward (Tukey: $p=0.02$ ), but GT controls and GT cocaine subjects did not differ on either measure (Tukey: CS,$+ p=0.94$; reward, $p=0.44$ ).

If DA release supports ST behaviors, then animals with the greatest ST should also show the greatest amounts of DA release to predictive cues. We assessed correlations between peak DA release from both core and shell to the cue and reward relative to average ST and GT behavior displayed by individual subjects (Fig. 10A-D). In controls, there was a significant positive correlation between the amount of ST behavior and DA release at the $\mathrm{CS}+(r=0.56, p=0.03$; Fig. $10 A)$, but not at the reward $(r=$ $0.08, p=0.77$; Fig. $10 B$ ), whereas there was no correlation between the rate of control GT behaviors and DA at CS $+(r=0.11$, $p=0.69$; Fig. $10 C)$ or reward $(r=0.004, p=0.99$; Fig. $10 D)$. In contrast, cocaine rats showed no significant correlations between DA release and ST or GT behaviors at either the CS+ (ST: $r=$ $0.06, p=0.85$, Fig. 10A; GT: $r=0.11, p=0.14$, Fig. 10C) or the reward (ST: $r=0.01, p=0.96$, Fig. $10 B$; GT: $r=0.03, p=0.92$, Fig. 10D). Indeed, during the CS + cue, the slope of the correlation between ST and DA in controls was significantly different from that in cocaine subjects, $F_{(1,24)}=6.32, p=0.02$ (Fig. $10 A$ ), but drug-based comparisons of correlational slopes were not different for ST and DA during reward (Fig. 10B) or for any GT comparisons (Fig. 10C,D; all ANOVA $p>0.20$ ).

Finally, we wanted to understand whether motivation for cocaine self-administration and total amount of drug intake was related to DA signaling on the Pavlovian task. Here, we assessed how the amount cocaine intake during self-administration (Fig. $11 \mathrm{~A}$ ) and the rate of drug-loading presses, which is considered a measure of motivation for the cocaine reward (Ahmed and Koob, 1998; Wheeler et al., 2008; Fig. 11B), was related to a measure of prediction error. We computed a prediction-error-type signal by subtracting DA evoked by the CS + from DA evoked by the reward. With this measure, the greater the DA release elicited by the reward relative to the cue, the greater the prediction error. We found that there was a strong positive correlation between this prediction error DA signal in the core and shell and the total cocaine intake during self-administration, $r=0.74, p=0.015$, 
A

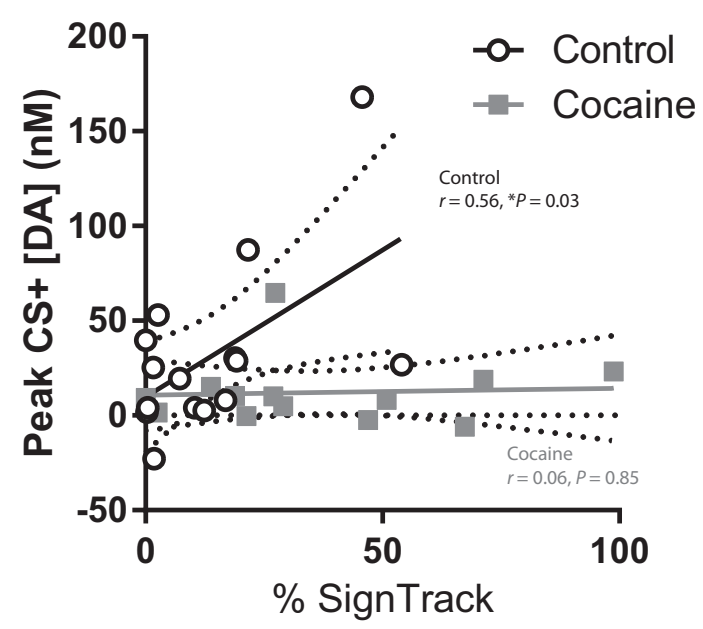

C

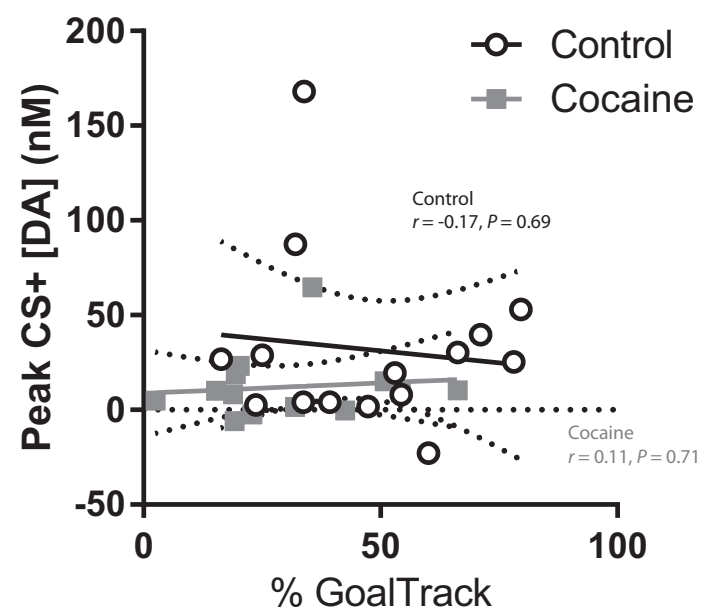

B

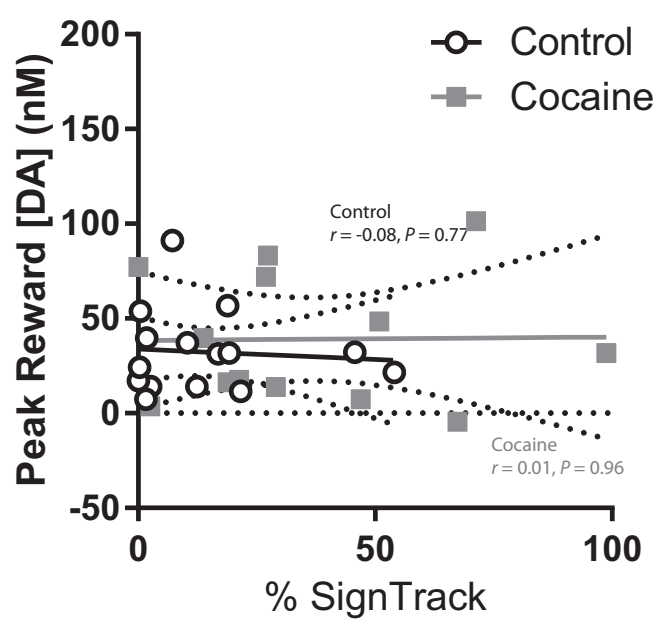

D

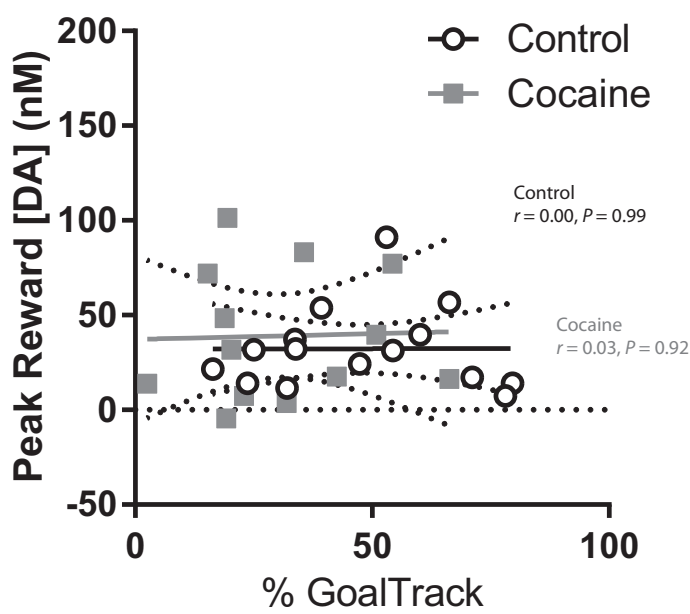

Figure 10. Correlations between peak DA release in both core and shell and approach behavior in $S T(A, B)$ and $G T(C, D)$ for the $C S+$ cue and the reward delivery. ST controls showed a significant correlation between cue-evoked DA and the rate of ST behavior, whereas ST cocaine subjects did not $(\boldsymbol{A})$, but DA did not correlate with reward delivery in either group $(\boldsymbol{B})$. The rate of GT behavior did not correlate with DA release to either the $C S+(C)$ or reward $(\boldsymbol{D})$ regardless of drug treatment.

A

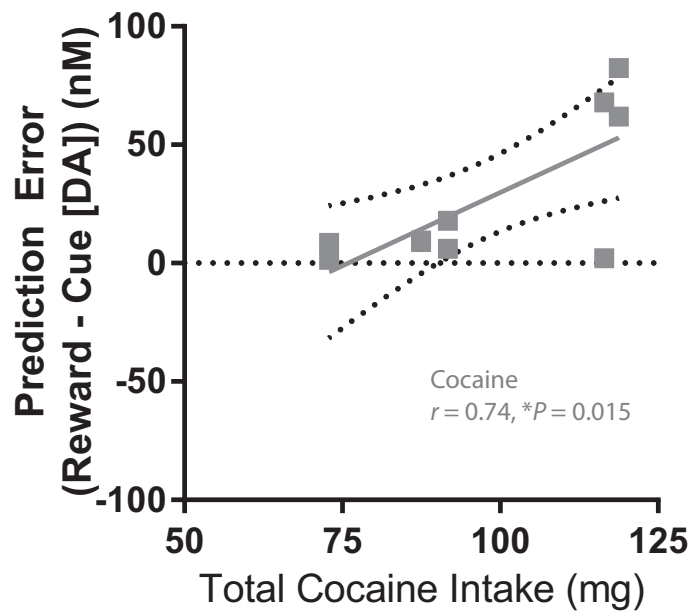

B

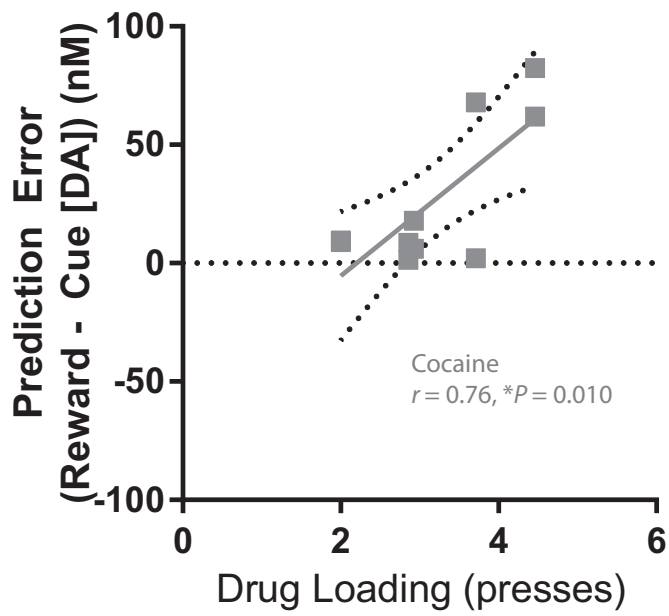

Figure 11. DA signals of prediction-error-type signal (i.e., DA at reward minus DA at cue) from both the core and shell were significantly correlated with the total amount of cocaine ingested during self-administration $(A)$ and the average number of drug loading presses (average number of presses made during the first 5 min of a session on the last 4 self-administration days) during stable self-administration $(\boldsymbol{B})$. 
indicating that, as rats self-administered more cocaine, they became more likely to encode reward rather than cue information. Likewise, the rate of drug loading was strongly correlated with the prediction error signal, $r=0.76, p=0.010$, suggesting that higher motivation for drug taking similarly shifted rats away from normal DA encoding patterns. Consistent with drug loading being a measure of motivation, the rate of loading was strongly positively correlated with the number of presses in extinction $(r=0.89, p=$ $0.0005)$, but the relationship between total drug intake and extinction pressing did not reach significance $(r=0.53, p=0.12)$.

\section{Discussion}

Here, cocaine self-administration induced abnormal effects on both patterns of DA release within NAc subregions and on various aspects of DA-linked associative behaviors. Specifically, whereas core DA release in controls displayed encoding that both discriminated between different cues and was biased toward the encoding of cues rather than rewards, cocaine experience impaired the ability for phasic DA release in the NAc core to discriminate between cues and instead biased release toward encoding of reward delivery. In contrast, phasic DA release in the shell was almost completely abolished in cocaine-experienced rats, whereas in controls, DA release was robust for both cue and reward and discriminated between cue type. Surprisingly, cocaine appeared to decouple the normal relationship between DA and conditioned approach. Although increased DA release for the CS + cue positively correlated with the rate of ST behavior in controls, cocaine subjects failed to show this relationship. Strikingly, cocaine rats displayed significantly greater rates of ST behavior than controls while simultaneously releasing less DA to reward-predictive cues. Collectively, these findings suggest that cocaine experience is capable of fundamentally and persistently altering the dynamics of multiple DA signals in the NAc, making it likely that these abnormal signals may contribute to the cognitive deficits and altered decision-making behavior exhibited by chronic cocaine addicts.

Cocaine self-administration experience altered various aspects of conditioned Pavlovian behavior. Consistent with previous reports (Saddoris and Carelli, 2014), cocaine-experienced rats successfully learned a first-order association $(\mathrm{CS}+/$ food), but were unable to learn a second-order association (SOC+/ $\mathrm{CS}+$ ). More surprisingly, we found that first-order conditioned approach behaviors strikingly varied between cocaine and control groups; cocaine rats preferentially displayed ST behaviors for Pavlovian food associations, whereas controls were more likely to display GT behaviors.

Previous work has suggested that individual differences in approach behaviors are an intrinsic feature of the animal. For example, rats identified as ST in a food-based conditioned approach task show greater sensitivity to subsequently trained cocaine-conditioned cues than GT rats (Saunders and Robinson, 2010; Meyer et al., 2012a; Yager and Robinson, 2013), suggesting that the shape of the conditioned approach behavior is consistent within a subject across multiple CS-US contingencies. Here, however, because our rats were randomly assigned to a drug condition, our findings support the idea that cocaine experience significantly alters individual response biases. Consistent with this, whereas previously identified ST rats showed a greater overall approach to cocaine cues than GT rats, both GT and ST rats showed a significant increase in ST behaviors after repeated cocaine exposure in a dose-dependent manner (Yager and Robinson, 2013). Similarly, previous experience with alcohol (McClory and Spear, 2014; Spoelder et al., 2015) or amphetamine (Robin- son et al., 2015) induces increases in ST in subsequent foodpaired conditioning procedures. Therefore, the ability for drugs to push subjects into an ST phenotype may illuminate why relapse is such a common feature of drug addiction. For drugexperienced animals, cues can become endowed with powerful motivational significance and elicit intense feelings of craving to resume drug taking (Wheeler et al., 2011). Although ST animals are inherently already at elevated risk of relapse (Yager and Robinson, 2013; Saunders et al., 2014), repeated drug intake appears to shift even GT animals into a more ST behavioral mode, thereby establishing a vicious cycle wherein more drug intake increases the likelihood of ST behaviors, which then may induce more stimulus-driven craving and higher incidence of relapse.

Against this behavioral background, DA release in the core and shell exhibited a complex relationship with ST and GT behaviors. In controls, cue-related DA release was potentiated in ST relative to GT, consistent with previous work (Flagel et al., 2011). For ST control rats, DA release during the $\mathrm{CS}+$ was greater than at reward and was also greater than at the CS+ for GT controls. In contrast, GT controls showed similar levels of DA release to the CS+ and reward. Indeed, the amount of DA released during the cue reliably predicted the proportion of time the control rats spent displaying ST, but not GT, behaviors. That these factors were true in both the core and shell suggests that enhanced ST-related DA release is a general feature of mesolimbic DA signaling rather than necessarily being confined to core- or shell-specific circuits.

Cocaine differentially affected these normal DA release dynamics by region. In the shell, cocaine-experienced rats failed to produce phasic DA release relative to cues and rewards, instead remaining near baseline levels for all stimuli. The NAc shell is particularly important for mediating the effects of drug reward because rats will preferentially self-administer drugs of abuse directly into the shell compared with the core (Ikemoto, 2002, 2003, 2007). However, this property may also make the shell more vulnerable to neuroplastic changes associated with chronic drug abuse (Mateo et al., 2005; Lack et al., 2008; Chuhma et al., 2014). In the present experiment, we failed to find reliable correlations of DA levels with any behavioral measures. Despite abolished DA signaling, cocaine rats were capable of performing conditioned behaviors similar to controls (although with higher ST than GT), suggesting that DA release dynamics in the shell are not necessary for these behaviors. These findings mirror our previous findings showing that NAc shell neurons in cocaineexperienced rats failed to encode associative representations despite apparently normal Pavlovian behavior (Saddoris and Carelli, 2014).

In the core, cocaine rats displayed phasic DA release that, although above baseline, was lower than control DA release at cues, failed to distinguish between the rewarded CS + and unreinforced CS - trials, and displayed exaggerated DA release to the reward delivery. However, overall (summated) DA release for the $\mathrm{CS}+$ and reward was similar between cocaine and control subjects. This suggests that an important aspect of cocaine-induced deficits in phasic DA release dynamics in the core during conditioning is related to inappropriate timing. Reward prediction error models describe how value-based predictions shifts to predictive cues as learning accrues and it has been proposed that DA release may provide the neural basis for this learning signal (Schultz et al., 1997; Pan et al., 2005; Niv and Schoenbaum, 2008; Enomoto et al., 2011; Saddoris et al., 2015a). Although controls displayed normal cue-shifted prediction encoding, DA release in cocaine rats was similar to that seen in the early stages of learning (day et al., 2007; Saddoris et al., 2015a) and provides some evidence that abnormally large prediction error coding at reward in drug-experienced populations may contribute to entrenchment 
of addiction (Redish, 2004). As in the shell, because cocaine rats were unimpaired at learning the first-order association, it appears that simple conditioning can proceed in the absence of appropriate core DA signals, but this learning is impoverished relative to normal animals because it is unable to support higher-order associations.

It is unclear how cocaine experience contributes to deficits in signaling and behavior because evidence from drug-naive rats suggests that core DA is essential for motivated behavior (Ostlund et al., 2014). In a compelling study, Saunders and Robinson (2012) showed that pharmacological blockade of DA receptors in the core impaired the ability of rats to perform ST on a learned conditioned approach task even on the first trial after the infusion, indicating that the changes in ST could not be explained by feedback during learning in the DA-blocked state. Here, however, we found the opposite result: cocaine-experienced animals with diminished (core) or completely abolished (shell) DA showed significantly enhanced ST behavior relative to controls.

One possible explanation for this disparity is that cocaine experience induces long-term neuroplastic changes in the VTANAc pathway that typically underlies normal goal-directed behaviors. Therefore, this region can no longer encode normal associative information and behavioral control shifts to a competing region. In support of this, Takahashi et al. (2007) demonstrated that striatal representations for instrumental goaldirected actions in cocaine-experienced rats sharply decreased in the NAc core while simultaneously increasing in the dorsal striatum (DS). Likewise, DA signaling for cocaine-associated cues shows a similar shift to the DS over repeated training (Willuhn et al., 2012; Willuhn et al., 2014). The DS predominantly receives dopaminergic input from the substantia nigra rather than from the VTA, suggesting that the VTA and related circuits may be particularly impaired after cocaine experience. Therefore, it is interesting that systemic L-DOPA administration improved phasic DA release in the dorsal striatum while also blunting escalation of drug intake in cocaine-experienced rats (Willuhn et al., 2014). Consistent with the putative DS shift, cocaine-experienced (and ST-shifted) animals are less flexible and show approach behavior that is less linked to features of the outcome (Schoenbaum et al., 2004; Schoenbaum and Setlow, 2005; Calu et al., 2007; Stalnaker et al., 2007b), which is consistent with more habit-like behaviors that are thought to involve DS circuits (Belin et al., 2009; Gremel and Costa, 2013). In the present study, the significant increase in ST behaviors via DS mechanisms presents an intriguing mechanism that will be explored in future studies.

\section{References}

Ahmed SH, Koob GF (1998) Transition from moderate to excessive drug intake: change in hedonic set point. Science 282:298-300. CrossRef Medline

Asensio S, Romero MJ, Romero FJ, Wong C, Alia-Klein N, Tomasi D, Wang GJ, Telang F, Volkow ND, Goldstein RZ (2010) Striatal dopamine D2 receptor availability predicts the thalamic and medial prefrontal responses to reward in cocaine abusers three years later. Synapse 64: 397-402. CrossRef Medline

Belin D, Jonkman S, Dickinson A, Robbins TW, Everitt BJ (2009) Parallel and interactive learning processes within the basal ganglia: relevance for the understanding of addiction. Behav Brain Res 199:89-102. CrossRef Medline

Boettiger CA, Mitchell JM, Tavares VC, Robertson M, Joslyn G, D’Esposito M, Fields HL (2007) Immediate reward bias in humans: fronto-parietal networks and a role for the catechol-O-methyltransferase 158(Val/Val) genotype. J Neurosci 27:14383-14391. CrossRef Medline

Cacciapaglia F, Saddoris MP, Wightman RM, Carelli RM (2012) Differential dopamine release dynamics in the nucleus accumbens core and shell track distinct aspects of goal-directed behavior for sucrose. Neuropharmacology 62:2050-2056. CrossRef Medline

Calu DJ, Stalnaker TA, Franz TM, Singh T, Shaham Y, Schoenbaum G (2007) Withdrawal from cocaine self-administration produces long-lasting deficits in orbitofrontal-dependent reversal learning in rats. Learn Mem 14: 325-328. CrossRef Medline

Canavan SV, Forselius EL, Bessette AJ, Morgan PT (2014) Preliminary evidence for normalization of risk taking by modafinil in chronic cocaine users. Addict Behav 39:1057-1061. CrossRef Medline

Chuhma N, Mingote S, Moore H, Rayport S (2014) Dopamine neurons control striatal cholinergic neurons via regionally heterogeneous dopamine and glutamate signaling. Neuron 81:901-912. CrossRef Medline

Day JJ, Roitman MF, Wightman RM, Carelli RM (2007) Associative learning mediates dynamic shifts in dopamine signaling in the nucleus accumbens. Nat Neurosci 10:1020-1028. CrossRef Medline

Di Chiara G, Imperato A (1988) drugs abused by humans preferentially increase synaptic dopamine concentrations in the mesolimbic system of freely moving rats. Proc Natl Acad Sci U S A 85:5274-5278. CrossRef Medline

Ehrman RN, Robbins SJ, Childress AR, O'Brien CP (1992) Conditioned responses to cocaine-related stimuli in cocaine abuse patients. Psychopharmacology 107:523-529. CrossRef Medline

Enomoto K, Matsumoto N, Nakai S, Satoh T, Sato TK, Ueda Y, Inokawa H, Haruno M, Kimura M (2011) Dopamine neurons learn to encode the long-term value of multiple future rewards. Proc Natl Acad Sci U S A 108:15462-15467. CrossRef Medline

Flagel SB, Clark JJ, Robinson TE, Mayo L, Czuj A, Willuhn I, Akers CA, Clinton SM, Phillips PE, Akil H (2011) A selective role for dopamine in stimulus-reward learning. Nature 469:53-57. CrossRef Medline

Goldstein RZ, Alia-Klein N, Tomasi D, Zhang L, Cottone LA, Maloney T, Telang F, Caparelli EC, Chang L, Ernst T, Samaras D, Squires NK, Volkow ND (2007) Is decreased prefrontal cortical sensitivity to monetary reward associated with impaired motivation and self-control in cocaine addiction? Am J Psychiatry 164:43-51. CrossRef Medline

Gremel CM, Costa RM (2013) Orbitofrontal and striatal circuits dynamically encode the shift between goal-directed and habitual actions. Nat Commun 4:2264. Medline

Ikemoto S (2002) Ventral striatal anatomy of locomotor activity induced by cocaine, D-amphetamine, dopamine and D1/D2 agonists. Neuroscience 113:939-955. CrossRef Medline

Ikemoto S (2003) Involvement of the olfactory tubercle in cocaine reward: intracranial self-administration studies. J Neurosci 23:9305-9311. Medline

Ikemoto S (2007) Dopamine reward circuitry: two projection systems from the ventral midbrain to the nucleus accumbens-olfactory tubercle complex. Brain Res Rev 56:27-78. CrossRef Medline

Jentsch JD, Olausson P, De La Garza R 2nd, Taylor JR (2002) Impairments of reversal learning and response perseveration after repeated, intermittent cocaine administrations to monkeys. Neuropsychopharmacology 26 : 183-190. CrossRef Medline

Kelm MK, Boettiger CA (2013) Effects of acute dopamine precusor depletion on immediate reward selection bias and working memory depend on catechol-O-methyltransferase genotype. J Cogn Neurosci 25:2061-2071. CrossRef Medline

Konova AB, Moeller SJ, Tomasi D, Parvaz MA, Alia-Klein N, Volkow ND, Goldstein RZ (2012) Structural and behavioral correlates of abnormal encoding of money value in the sensorimotor striatum in cocaine addiction.Eur J Neurosci 36:2979-2988.

Koob GF (2015) The dark side of emotion: the addiction perspective. Eur J Pharmacol 753:73-87. CrossRef Medline

Lack CM, Jones SR, Roberts DC (2008) Increased breakpoints on a progressive ratio schedule reinforced by IV cocaine are associated with reduced locomotor activation and reduced dopamine efflux in nucleus accumbens shell in rats. Psychopharmacology 195:517-525. Medline

LeBlanc KH, Maidment NT, Ostlund SB (2013) Repeated cocaine exposure facilitates the expression of incentive motivation and induces habitual control in rats. PLoS One 8:e61355. CrossRef Medline

Mateo Y, Lack CM, Morgan D, Roberts DC, Jones SR (2005) Reduced dopamine terminal function and insensitivity to cocaine following cocaine binge self-administration and deprivation. Neuropsychopharmacology 30:1455-1463. CrossRef Medline

McClory AJ, Spear LP (2014) Effects of ethanol exposure during adoles- 
cence or in adulthood on Pavlovian conditioned approach in SpragueDawley rats. Alcohol 48:755-763. CrossRef Medline

Meyer PJ, Ma ST, Robinson TE (2012a) A cocaine cue is more preferred and evokes more frequency-modulated $50-\mathrm{kHz}$ ultrasonic vocalizations in rats prone to attribute incentive salience to a food cue. Psychopharmacology 219:999-1009. CrossRef Medline

Meyer PJ, Lovic V, Saunders BT, Yager LM, Flagel SB, Morrow JD, Robinson TE (2012b) Quantifying individual variation in the propensity to attribute incentive salience to reward cues. PLoS One 7:e38987. CrossRef Medline

Moeller SJ, Tomasi D, Honorio J, Volkow ND, Goldstein RZ (2012a) Dopaminergic involvement during mental fatigue in health and cocaine addiction. Transl Psychiatry 2:e176. CrossRef Medline

Moeller SJ, Hajcak G, Parvaz MA, Dunning JP, Volkow ND, Goldstein RZ (2012b) Psychophysiological prediction of choice: relevance to insight and drug addiction. Brain 135:3481-3494. CrossRef Medline

Niv Y, Schoenbaum G (2008) Dialogues on prediction errors. Trends Cogn Sci 12:265-272. CrossRef Medline

Ostlund SB, LeBlanc KH, Kosheleff AR, Wassum KM, Maidment NT (2014) Phasic mesolimbic dopamine signaling encodes the facilitation of incentive motivation produced by repeated cocaine exposure. Neuropsychopharmacology 39:2441-2449. CrossRef Medline

Pan WX, Schmidt R, Wickens JR, Hyland BI (2005) Dopamine cells respond to predicted events during classical conditioning: evidence for eligibility traces in the reward-learning network. J Neurosci 25:6235-6242. CrossRef Medline

Pickens CL, Airavaara M, Theberge F, Fanous S, Hope BT, Shaham Y (2011) Neurobiology of the incubation of drug craving. Trends Neurosci 34: 411-420. CrossRef Medline

Redish AD (2004) Addiction as a computational process gone awry. Science 306:1944-1947. CrossRef Medline

Robbins SJ, Ehrman RN, Childress AR, Cornish JW, O’Brien CP (2000) Mood state and recent cocaine use are not associated with levels of cocaine cue reactivity. Drug Alcohol Depend 59:33-42. CrossRef Medline

Robinson MJ, Anselme P, Suchomel K, Berridge KC (2015) Amphetamineinduced sensitization and reward uncertainty similarly enhance incentive salience for conditioned cues. Behav Neurosci 129:502-511. CrossRef Medline

Rodeberg NT, Johnson JA, Cameron CM, Saddoris MP, Carelli RM, Wightman RM (2015) Construction of training sets for valid calibration of in vivo cyclic voltammetric data by principal component analysis. Anal Chem 87:11484-11491. CrossRef Medline

Saddoris MP, Carelli RM (2014) Cocaine self-administration abolishes associative neural encoding in the nucleus accumbens necessary for higherorder learning. Biol Psychiatry 75:156-164. CrossRef Medline

Saddoris MP, Stamatakis A, Carelli RM (2011) Neural correlates of Pavlovian-to-instrumental transfer in the nucleus accumbens shell are selectively potentiated following cocaine self-administration. Eur J Neurosci 33:2274-2287. CrossRef Medline

Saddoris MP, Sugam JA, Cacciapaglia F, Carelli RM (2013) Rapid dopamine dynamics in the accumbens core and shell: learning and action. Front Biosci (Elite Ed) 5:273-288. Medline

Saddoris MP, Cacciapaglia F, Wightman RM, Carelli RM (2015a) Differential dopamine release dynamics in the nucleus accumbens core and shell reveal complementary signals for error prediction and incentive motivation. J Neurosci 35:11572-11582. CrossRef Medline

Saddoris MP, Sugam JA, Stuber GD, Witten IB, Deisseroth K, Carelli RM (2015b) Mesolimbic dopamine dynamically tracks, and is causally linked to, discrete aspects of value-based decision making. Biol Psychiatry 77: 903-911. CrossRef Medline

Saunders BT, Robinson TE (2010) A cocaine cue acts as an incentive stimulus in some but not others: implications for addiction. Biol Psychiatry 67:730-736. CrossRef Medline

Saunders BT, Robinson TE (2012) The role of dopamine in the accumbens core in the expression of Pavlovian-conditioned responses. Eur J Neurosci 36:2521-2532. CrossRef Medline

Saunders BT, O’Donnell EG, Aurbach EL, Robinson TE (2014) A cocaine context renews drug seeking preferentially in a subset of individuals. Neuropsychopharmacology 39:2816-2823. Medline

Schoenbaum G, Setlow B (2005) Cocaine makes actions insensitive to out- comes but not extinction: implications for altered orbitofrontalamygdalar function. Cereb Cortex 15:1162-1169. Medline

Schoenbaum G, Saddoris MP, Ramus SJ, Shaham Y, Setlow B (2004) Cocaine-experienced rats exhibit learning deficits in a task sensitive to orbitofrontal cortex lesions. Eur J Neurosci 19:1997-2002. CrossRef Medline

Schultz W, dayan P, Montague PR (1997) A neural substrate of prediction and reward. Science 275:1593-1599. CrossRef Medline

Setlow B, Mendez IA, Mitchell MR, Simon NW (2009) Effects of chronic administration of drugs of abuse on impulsive choice (delay discounting) in animal models. Behav Pharmacol 20:380-389. CrossRef Medline

Shrout PE, Fleiss JL (1979) Intraclass correlations: uses in assessing rater reliability. Psychol Bull 86:420-428. CrossRef Medline

Simon NW, Mendez IA, Setlow B (2007) Cocaine exposure causes longterm increases in impulsive choice. Behav Neurosci 121:543-549. CrossRef Medline

Spoelder M, Tsutsui KT, Lesscher HM, Vanderschuren LJ, Clark JJ (2015) Adolescent alcohol exposure amplifies the incentive value of rewardpredictive cues through potentiation of phasic dopamine signaling. Neuropsychopharmacology 40:2873-2885. CrossRef Medline

Stalnaker TA, Roesch MR, Calu DJ, Burke KA, Singh T, Schoenbaum G (2007a) Neural correlates of inflexible behavior in the orbitofrontalamygdalar circuit after cocaine exposure. Ann NY Acad Sci 1121: 598-609. CrossRef Medline

Stalnaker TA, Roesch MR, Franz TM, Calu DJ, Singh T, Schoenbaum G (2007b) Cocaine-induced decision-making deficits are mediated by miscoding in basolateral amygdala. Nat Neurosci 10:949-951. CrossRef Medline

Sugam JA, day JJ, Wightman RM, Carelli RM (2012) Phasic nucleus accumbens dopamine encodes risk-based decision-making behavior. Biol Psychiatry 71:199-205. CrossRef Medline

Sugam JA, Saddoris MP, Carelli RM (2014) Nucleus accumbens neurons track behavioral preferences and reward outcomes during risky decision making. Biol Psychiatry 75:807-816. CrossRef Medline

Takahashi Y, Roesch MR, Stalnaker TA, Schoenbaum G (2007) Cocaine exposure shifts the balance of associative encoding from ventral to dorsolateral striatum. Front Integr Neurosci 1:pii:nihpa51247. Medline

Twining RC, Wheeler DS, Ebben AL, Jacobsen AJ, Robble MA, Mantsch JR, Wheeler RA (2015) Aversive stimuli drive drug seeking in a state of low dopamine tone. Biol Psychiatry 77:895-902. CrossRef Medline

Vadhan NP, Hart CL, Haney M, van Gorp WG, Foltin RW (2009) Decisionmaking in long-term cocaine users: Effects of a cash monetary contingency on Gambling task performance. Drug Alcohol Depend 102:95-101. CrossRef Medline

Volkow ND, Fowler JS, Wang GJ, Hitzemann R, Logan J, Schlyer DJ, Dewey SL, Wolf AP (1993) Decreased dopamine D2 receptor availability is associated with reduced frontal metabolism in cocaine abusers. Synapse 14:169-177. CrossRef Medline

Volkow ND, Wang GJ, Fowler JS, Logan J, Hitzemannn R, Gatley SJ, MacGregor RR, Wolf AP (1996) Cocaine uptake is decreased in the brain of detoxified cocaine abusers. Neuropsychopharmacology 14: 159-168. CrossRef Medline

Wheeler RA, Twining RC, Jones JL, Slater JM, Grigson PS, Carelli RM (2008) Behavioral and electrophysiological indices of negative affect predict cocaine self-administration. Neuron 57:774-785. CrossRef Medline

Wheeler RA, Aragona BJ, Fuhrmann KA, Jones JL, day JJ, Cacciapaglia F, Wightman RM, Carelli RM (2011) Cocaine cues drive opposing context-dependent shifts in reward processing and emotional state. Biol Psychiatry 69:1067-1074. CrossRef Medline

Willuhn I, Burgeno LM, Everitt BJ, Phillips PE (2012) Hierarchical recruitment of phasic dopamine signaling in the striatum during the progression of cocaine use. Proc Natl Acad Sci U S A 109:20703-20708. CrossRef Medline

Willuhn I, Burgeno LM, Groblewski PA, Phillips PE (2014) Excessive cocaine use results from decreased phasic dopamine signaling in the striatum. Nat Neurosci 17:704-709. CrossRef Medline

Wolf ME, Tseng KY (2012) Calcium-permeable AMPA receptors in the VTA and nucleus accumbens after cocaine exposure: when, how, and why? Front Mol Neurosci 5:72. Medline

Yager LM, Robinson TE (2013) A classically conditioned cocaine cue acquires greater control over motivated behavior in rats prone to attribute incentive salience to a food cue. Psychopharmacology 226:217-228. CrossRef Medline 